NBER WORKING PAPER SERIES

\title{
UNDERSTANDING THE ECONOMIC CONSEQUENCES OF SHIFTING TRENDS IN POPULATION HEALTH
}

\author{
Pierre-Carl Michaud \\ Dana Goldman \\ Darius Lakdawalla \\ Yuhui Zheng \\ Adam Gailey \\ Working Paper 15231 \\ http://www.nber.org/papers/w15231
}

\author{
NATIONAL BUREAU OF ECONOMIC RESEARCH \\ 1050 Massachusetts Avenue \\ Cambridge, MA 02138 \\ August 2009
}

This research was funded by Employee Benefits Security Administration US Department of Labor through Contract J-9-P-2-0033. Corresponding author: Pierre-Carl Michaud, michaud@ rand.org, 1776 Main Street, Santa Monica, CA 90407-2138, United States, Tel: +1 (310) 393-0411 extension 7620. The authors are solely responsible for the content. The views expressed herein are those of the author(s) and do not necessarily reflect the views of the National Bureau of Economic Research.

NBER working papers are circulated for discussion and comment purposes. They have not been peerreviewed or been subject to the review by the NBER Board of Directors that accompanies official NBER publications.

(C) 2009 by Pierre-Carl Michaud, Dana Goldman, Darius Lakdawalla, Yuhui Zheng, and Adam Gailey. All rights reserved. Short sections of text, not to exceed two paragraphs, may be quoted without explicit permission provided that full credit, including $\odot$ notice, is given to the source. 
Understanding the Economic Consequences of Shifting Trends in Population Health Pierre-Carl Michaud, Dana Goldman, Darius Lakdawalla, Yuhui Zheng, and Adam Gailey NBER Working Paper No. 15231

August 2009

JEL No. I10,I38,J26

\begin{abstract}
$\underline{\text { ABSTRACT }}$
The public economic burden of shifting trends in population health remains uncertain. Sustained increases in obesity, diabetes, and other diseases could reduce life expectancy - with a concomitant decrease in the public-sector's annuity burden - but these savings may be offset by worsening functional status, which increases health care spending, reduces labor supply, and increases public assistance. Using a microsimulation approach, we quantify the competing public-finance consequences of shifting trends in population health for medical care costs, labor supply, earnings, wealth, tax revenues, and government expenditures (including Social Security and income assistance). Together, the reduction in smoking and the rise in obesity have increased net public-sector liabilities by $\$ 430 \mathrm{bn}$, or approximately $4 \%$ of the current debt burden. Larger effects are observed for specific public programs: annual spending is $10 \%$ higher in the Medicaid program, and 7\% higher for Medicare.
\end{abstract}

Pierre-Carl Michaud

The RAND Corporation

1776 Main Street

Santa Monica, CA 90401

michaud@rand.org

Dana Goldman

The RAND Corporation

1776 Main Street

P.O. Box 2138

Santa Monica, CA 90407-2138

and NBER

dgoldman@ rand.org

Darius Lakdawalla

The RAND Corporation

1776 Main Street

Santa Monica, CA 90407-2138

and NBER

darius@ rand.org
Yuhui Zheng

The RAND Corporation

1776 Main Street

Santa Monica, CA 90401

zheng@rand.org

Adam Gailey

The RAND Corporation

1776 Main Street

P.O. Box 2138

Santa Monica, CA 90401

agailey@ rand.org 


\section{A. Introduction}

Over the past century, the US has enjoyed unprecedented improvements in health and longevity. Over the past several decades, however, the skies have begun to darken, as a result of rising obesity and diabetes, and worsening functional status among younger cohorts (Mokdad et al., 2001; Lakdawalla et al., 2005) . Much has been made about the resulting poor health status of Americans, compared to their counterparts in the rest of the developed world (Banks et al., 2006; Michaud et al., 2007). At the same time, however, rates of smoking have declined substantially, presumably to the benefit of overall health. The net effect of these large and offsetting trends remains uncertain, as does the future health and longevity of Americans. Meanwhile, the precarious financial position of the public sector, along with its mounting annuity and medical cost liabilities, raises the policy stakes around the uncertain trends in health and longevity.

The interplay among health, longevity, individual decision making, and public programs is both complex and vitally important to policy. Therefore, we examine how emerging trends in health, along with possible scenarios for health improvement, are likely to affect future health, longevity, savings, retirement, and public-sector liabilities over the next 50 years. We base our investigation on the Future Elderly Model (FEM), which serves as an engine for modeling the dynamics of population health, longevity, medical spending, and labor force participation (Goldman et al., 2005). The model can answer a series of "what-if" questions by forecasting health and economic outcomes in the future.

Our analysis suggests that, while obesity growth and smoking reduction have offsetting effects on longevity and health, they both have deleterious effects on the public purse. The key insight is into the timing and duration of mortality and morbidity effects, which vary for obesity and smoking. Increases in obesity reduce life expectancy and thus, in principle, save money for the annuity system. However, they also increase morbidity for a number of years before death. The present value of the increase in medical expenditures outweighs the increase in annuity expenditures, which occurs 
farther into the future. On the other side of the ledger, federal revenues rise but fall short of financing the additional public expenditures.

Unfortunately for public budgets, smoking reductions represent a different but equally challenging kind of problem. While reduced smoking lowers both mortality and morbidity risk, the morbidity suffered by smokers tends to be compressed in the year or two prior to death. Therefore, the increased burden on the annuity system outweighs this relatively small reduction in medical expenditures. Reduced smoking on the other hand increases revenues, which finances part of the increased annuity burden. Overall, the net effect is an increase in public liabilities. In sum, both these recent trends in health while apparently very different for private health and welfare - lead to the same troubling impact on public finances.

We use a microsimulation model to estimate the public-finance consequences of trends in smoking, obesity, and its related comorbidities. We first project the likely public finance consequences of continuing trends in smoking, obesity, diabetes, and hypertension. Next, we compare this "status quo" projection to one in which all these health outcomes are "rolled back" to their 1978 levels, before the recent run-up in obesity and the substantial decline in smoking. We find that, if one were to roll obesity and smoking back to their 1978 levels by 2030, public health care spending would fall significantly, although this would be partially offset by reductions in tax revenue. In particular, the "roll-backs" would lower annual Medicaid spending by $10 \%$, and annual Medicare spending by $7 \%$. While they also lower Federal payroll and income tax collections, even in total, these are only about one-third the absolute size of the effect on Medicaid, and one-sixth the effect on Medicare. Overall, we project these two trends together have added approximately $4 \%$ to the US national debt.

The paper is structured as follow. Section B describes current trends in health in the U.S. Section C describes the model that is used to describe the long-term economic consequences of these trends. Section D uses the model to quantify the impacts of the scenarios described above, and Section E discusses the results. 


\section{B. Health Trends in the U.S.}

The United States and other developed countries have experienced large gains in lifeexpectancy over the last century. For example, life expectancy at birth increased from 61 years in 1933 to 78 years in $2004 .^{2}$ The first 50 years of the 20th century were marked by a strong decline in infectious diseases which greatly decreased mortality rates, particularly for the young. In the second half of the century, medical technology has been a critical factor behind further improvements in life expectancy, by reducing mortality rates among older age groups. But over the last 30 years, chronic illnesses associated with more sedentary lifestyles have spread, somewhat mitigating those advances. These trends are particularly pronounced in the United States (Bhattacharya et al., 2004).

On the other hand, recent declines in the prevalence of smoking have benefited public health. In addition, old-age disability generally receded during the 1980s and 1990s. Figure 1 summarizes the recent trends by showing the prevalence of life-time smoking, obesity, diabetes, and hypertension over the last 10 years among the elderly population. We use data from the National Heath Interview Surveys (NHIS) of 1997 to 2006 and focus on the population older than $50 .^{3}$

In 1997, the fraction of individuals 50 years of age or older who were obese (BMI of $30 \mathrm{~kg} / \mathrm{m}^{2}$ or more) was $23.2 \%$. By 2006 , this had risen to $31.8 \%$. One study projects that if this trend continues, roughly one-half of Americans between the ages of 45 and 64 will be obese by 2050, which places them at great risk of developing conditions such as diabetes, hypertension, heart disease and stroke (Ruhm, 2007). For example, only 5.5\% of Americans aged 45-64 had Type-2 diabetes in 1980 according to the Centers for Disease Control and Prevention. Since then, the prevalence of this disease has roughly doubled, in a space of less than 25 years (10.2\% in 2005).

The same figure makes clear that we continue to see a reduction in the prevalence of smoking, which will lead to less cancer and cardiovascular disease. As a consequence, future overall health trends remain uncertain, and will depend upon the interplay between

\footnotetext{
${ }^{2}$ Based on life tables collected in the Human Mortality Database (www.mortality.org).

${ }^{3}$ The formulation of some of the questions in the NHIS was different prior to 1997. Further historical evidence is published elsewhere (e.g. Centers for Disease Control and Prevention).
} 
favorable trends in smoking (and perhaps in elderly disability), and unfavorable trends in obesity and related conditions. At a minimum, the mix of diseases afflicting the elderly population is likely to change over the next 20 years. Hence, non-trivial effects on lifeexpectancy and disability are likely to occur.

\section{Microsimulation Model of Health and Economic Dynamics}

\section{C.1 Background}

To assess the economic implications of these health trends, one needs a rich health and mortality transition model coupled with a model of economic outcomes. Both the epidemiological and economic literatures contain complex models of each, but few integrate both.

The current epidemiological literature features several well-known and complementary approaches for measuring population health and projecting future disease burden and mortality_-including models by Manton and co-authors (Manton et al., 1993), Lee (Lee, 2000), and Hayward (Hayward and Warner, 2005). Across these models, there is an underlying trade-off between the complexity of the data required, and the broad applicability of the model. For instance, early life table approaches like those of Sullivan (1971) require only age-specific population data as well as corresponding disability rates at those same ages; these elements are all present in cross-sectional data. However, these straightforward data requirements come at a cost, as the Sullivan method appears too insensitive to large changes in disability and mortality, and may thus underestimate future trends in population health (Bonneux et al., 1994). Multistate life table models and microsimulation models that exploit longitudinal data, however, can accommodate richer dynamics than Sullivan's method and thus provide more flexibility in modeling the dynamic interplay between morbidity, disability, and mortality. Such dynamic models obtain population health trends as aggregates from individual stochastic processes underlying these outcomes.

On the other hand, current models of economic decisions in old-age tend either to ignore or to take a very narrow view of health, which is often reduced to a self-reported 
indicator of "good" or "bad" health (Rust and Phelan, 1997; French, 2005). This constraint is typically imposed due to computational limitations, rather than by the preferences of the analyst. Dynamic structural models of economic decisions make a more detailed treatment of health computationally prohibitive. Microsimulation economic models such as the MINT model (Toder et al., 2002) and the CBO's CBOLT model (Oharra et al., 2004) either do not incorporate health or adopt a very narrow definition of it.

We propose a model that considers the dynamic interplay between a large number of health outcomes as well as economic outcomes. The model is an extension of the Future Elderly Model (FEM) developed at RAND (Goldman et al., 2004). This is a reduced-form markovian model that allows for unobserved heterogeneity and correlation across outcomes. In that sense, it is well-equipped to analyze the effect of the health trends in public financial liabilities, as it allows for complex interactions between multidimensional measures of health and economic outcomes.

\section{C.2 Functioning of the Dynamic Model}

\section{C.2.1 Overview}

The Future Elderly Model (FEM) was developed to examine health and health care costs among the elderly Medicare population (age 65+) (Goldman et al., 2004). The most recent versions now project these outcomes for all Americans aged 50 and older. The defining characteristic of the model is the modeling of real rather than synthetic cohorts, all of whom are followed at the individual level. This allows for more heterogeneity in behavior than would be allowed by a cell-based approach. Also, since the HRS interviews both respondent and spouse, we can link records to calculate household-level outcomes such as net income and Social Security retirement benefits, which depend on the outcomes of both spouses. The omission of the population younger than age 50 sacrifices little generality, since the bulk of expenditure on the public programs we consider occurs after age 50. However, we may fail to capture behavioral responses among the young.

The model has three core components: 
The initial cohort module predicts the financial and health outcomes of new cohorts of 50 year-olds. This module takes in data from the Health and Retirement Study (HRS) and trends calculated from other sources. It allows us to "generate" cohorts as the simulation proceeds, so that we can measure outcomes for the age 50+ population in any given year.

The transition module calculates the probabilities of transiting across various health states and financial outcomes. The module takes as inputs risk factors such as smoking, weight, age and education, along with lagged health and financial states. This allows for a great deal of heterogeneity and fairly general feedback effects. The transition probabilities are estimated from the longitudinal data in the Health and Retirement Study (HRS).

The policy outcomes module aggregates projections about individual-level outcomes into policy outcomes such as taxes, medical care costs, pension benefits paid, and disability benefits. This component takes account of public and private program rules to the extent allowed by the available outcomes. Because we have access to HRS-linked restricted data from Social Security records and employer pension plans, we are able to realistically model retirement benefit receipt.

Figure 2 provides a schematic overview of the model. We start in 2004 with an initial population aged 50+ taken from the HRS. We then predict outcomes using our estimated transition probabilities. Those who survive make it to the end of that year, at which point we calculate policy outcomes for the year. We then move to the following year, when a new cohort of 50 year-olds enters. This entrance forms the new age $50+$ population, which then proceeds through the transition model as before. This process is repeated until we reach the final year of the simulation.

\section{C.2.2 Initial Cohort Module}

Since we aim to characterize outcomes for the age 50+ population, we need to predict the characteristics of the 50 year-old population, in terms of health, demographics and economic outcomes. Unfortunately, the HRS does not include respondents younger than age 50; therefore, the characteristics of "future" 50 year-olds must be modeled and imputed from data on younger individuals. 
First, we estimate trends in the health of 50 year-olds using two methods. We use the method described in Goldman, Hurd et al. (2004) to calculate trends in disease prevalence from the National Health Interview Surveys (NHIS). The trends we estimate are relatively close to other independent estimates, as documented in the appendix. For outcomes other than disease prevalence, we use existing estimates, all of which are documented in the appendix. In Figure 3, the dotted lines represent our baseline projection for smoking and obesity.

Second, we use the 50 year-old HRS respondents from 2004 as a template for future cohorts of 50 year-olds. We "adjust" their health to match projected prevalence levels, using the trends estimated in the first step. For example, if obesity is projected to go up in 2020, we increase the rate of obesity within the cohort of 50 year-olds, by "reassigning" enough non-obese individuals to obesity status. Since obesity is correlated with other outcomes such as hypertension and diabetes, we reassign obesity status so that those at greatest risk are more likely to acquire it.

The reassignment is governed by a latent health model with correlated unobservables. An individual's disease status is a function of the mean population probability of the disease, along with a random error term. For an individual, the error terms are correlated across diseases. This builds in the possibility that, for instance, the occurrence of diabetes and hypertension are correlated. We jointly estimate the population means and the covariance structure of the error terms by maximum simulated likelihood (more details appear in the technical appendix). Table 2 lists all the outcomes that we model. There are seven binary outcomes: hypertension, heart disease, diabetes, fair or poor self-reported health, labor force participation, insurance status and positive wealth. (The inclusion of this last indicator is necessary because of the observed spike in the distribution of net wealth at zero in the HRS.) There are three ordered outcomes: BMI status, smoking status and functional status, defined as it is in the transition model. Finally, there are five continuous outcomes: average indexed monthly earnings (AIME), the number of quarters of coverage; earnings, financial wealth, and defined contribution (DC) wealth. We also model respondents' pension plan characteristics: whether they have a DB or DC plan on the current job; the earliest age at which they are eligible; and the normal retirement age. We group the latter around peaks in the empirical distribution. 
The most common early retirement age is 55 , and the most common normal retirement age is 62. Finally, each of these outcomes depends on fixed characteristics such as race, education, gender and marital status. We also consider cancer, lung disease and stroke as fixed covariates, because their prevalence is very low in this population (age 50-53).

Estimates are presented in the appendix.

Finally, the size of the entering cohort is adjusted to reflect population projections from Census by gender and race. We also adjust the size of the initial new cohort in 2004 to Census estimates by gender, race and ethnicity.

\section{C.2.3 Transition Model}

The transition model tracks movement among states as a function of risk and demographic factors. The technical appendix provides details on the parametric structure, estimation, and validation of the model. Here we enumerate and discuss all the key inputs and outputs of the model, and how they are measured.

The data come from the 1992 to 2004 biennial waves of the HRS. We consider both health and economic outcomes, all of which are listed in Table 1. The table lists several groups of variables: diseases, risk factors, functional status, labor force and benefit status, financial resources, nursing home residence, and death. At a particular point in an individual's life, the model takes as inputs the individual's risk factors, along with her lagged disease status, functional status, labor force and benefit status, financial resources, and nursing home status. The outputs are current disease status, functional status, labor force and benefit status, financial resources, and nursing home status. More detail on variable measurement is presented below.

Transition rates are allowed to differ across demographic and economic groups. In particular, we allow differences by gender, race and ethnicity, education, and marital status. Transition equations are estimated on 7 waves of the HRS. To assess the fit, we use estimated transition probabilities to simulate what 1992 HRS respondents would look like in 2004. We then compare these to actual outcomes. We use half the sample for estimation and the other half for simulation. In general, the model fits the data quite well, with a close correspondence between predicted and actual outcomes in most areas, including labor supply, claiming behavior, functional status, and diseases. Complete 
results can be found in Table A.9 of the technical appendix. We present more validation results later.

\section{Measurement of Variables}

The list of diseases includes the most prevalent conditions in the HRS survey: hypertension, stroke, heart disease, lung disease, diabetes and cancer. An individual's disease status is estimated using the responses to questions of the form: "Has a doctor ever told you that you had...." Consistent with the chronic nature of these illnesses, we assume there is no chance of recovery and model the time until diagnosis (after age 50).

Second, we consider risk factors, focusing particularly on smoking and obesity. We model transitions across three "obesity" states: not obese $(\mathrm{BMI}<25)$, overweight $(25-$ 30) and obese (BMI>30). This information is derived from self-reports on weight and height. ${ }^{4}$ For smoking, we model whether the respondent: has never smoked, has ever smoked but quit, or is still smoking at the time of the interview.

Third, we consider measures of functional status commonly known as ADL (activities of daily living) limitations and IADL (instrumental activities of daily living) limitations. These are counts of positive answers to questions (5 for ADL limitations and 7 for IADL limitations) such as whether the respondent has trouble walking, getting out of bed, dressing, etc. IADL's are typically less severe impairments than ADL's. We measure functional status by classifying respondents into the following categories: no IADL or ADL limitations, 1-2 IADL limitations but no ADL limitations, 1-2 ADL limitations, or 3+ ADL limitations. This classification scheme yields four mutually exclusive categories (based on the data). These are not assumed to be absorbing states in that we allow for recovery.

Next, we add labor force and benefit receipt outcomes. (We express all monetary units in terms of 2004 dollars using the Consumer Price Index.) First, we track whether someone works for pay (any positive hours), and we track earnings on the main job. We also track whether the respondent has employer-based health insurance, or derives coverage from other sources (apart from Medicare). We do this for the population younger than age 65 . After age 65 , nearly all respondents have insurance through

\footnotetext{
${ }^{4}$ We do not attempt to correct self-reports for measurement error (notoriously underreporting).
} 
Medicare. An individual can derive coverage through his employer, the employer of his/her spouse, a private insurer, or a government assistance program such as Medicaid (if disabled). We also record whether someone has a pension on his job, and whether this is a defined benefit (DB) or defined contribution (DC) type. If the respondent reports a DC pension, we also consider the self-reported account balance as another dependent variable. If the respondent reports a DB pension, we record the earliest age at which the pension can be claimed, as well as the number of years on the job and the normal retirement age on that plan. We also construct a variable recording whether someone is claiming a DB pension on the current job (quitting a job with a DB pension). Hence, we have 2 binary state variables (DC and DB entitlement) and one continuous state-variable (DC account balance) to take account of private pensions.

We model Social Security retirement benefit receipt using the self-reported age at which benefits were first claimed. Since we have access to earnings records for respondents in the HRS, we also determine who is eligible upon reaching age 62 using quarters of coverage. We construct the Average Indexed Monthly Earnings (AIME) for the initial interview and update the AIME in the simulation using a simplified rule as in French (2005). ${ }^{5}$ The AIME is the basis for computing benefits. We also model disability insurance (DI) benefit receipt and Supplemental Security Income (SSI) using self-reports from the HRS. When reporting SSI figures however, we use a measurement error correction model estimated from merging self-reported with administrative data from SSA to correct for underreporting (see Technical Appendix for details).

We then add measures of financial resources. We construct a measure of net financial wealth using self-reports from the HRS and imputations performed by RAND (Hurd et al., 1998). Net financial wealth is defined as the value of financial assets (checking, savings, stocks, IRAs, Certificate deposits, bonds) plus the value of real assets (primary house, other real estate, other real assets) minus all debt (mortgage, home loans, credit cards, etc). We also track earnings, and whether wealth is positive. To account for the skewness of the wealth and earnings distribution, we use the generalized inverse

\footnotetext{
${ }^{5}$ We estimate a regression function of next period's AIME as a function of baseline AIME and earnings. We allow coefficients to be age specific and consider a second-order approximation. Estimates available upon request.
} 
hyperbolic sine transformation (MacKinnon and Magee, 1990). For both wealth and earnings, we censor observations above the $99^{\text {th }}$ percentile in 2004.

Finally, we track nursing home residence, and mortality. The HRS initially did not sample from the nursing home population. However, it does follow respondents into nursing homes and also records transition back to independent or assisted living outside nursing homes. Mortality is recorded in exit interviews in the HRS. Mortality hazards derived from the HRS correspond closely with life-table probabilities (Adams et al., 2003; Michaud et al., 2006).

\section{Model Restrictions}

We make several restrictions on the transition risks permitted in the model. First, we only allow feedback from diseases where clinical research supports such a link. For example, we allow hypertensive patients to have higher risk of heart disease incidence, but we do not allow hypertensive patients to have higher risk of cancer. These clinical restrictions are documented in the technical appendix and elsewhere (Goldman et al., 2004).

Another important restriction we impose is that economic outcomes do not have feedback effects on health. This is consistent with the findings from previous studies (Adams et al., 2003). SES does not appear to have a causal effect on health outcomes in this age range. The correlation between SES and health appears to be generated by feedback effects from health to economic status, most notably through the effect of health shocks on labor supply and medical spending. Also playing a role are predetermined (earlier) events or common factors (genetics, etc) that induce a non-causal correlation between SES and health (Michaud and van Soest, 2008). These two factors are accounted for in the estimation.

\section{C.2.4 Policy Outcomes}

The model simulates a number of relevant health and economic outcomes for individuals. First, we consider a set of health outcomes such as life-expectancy and healthy life expectancy (no ADL) at age 50 and medical expenditures. Average medical expenditures by disease and demographic group are calculated from two sources. For those younger than age 65, we use the Medical Expenditure Panel Survey (MEPS) and include in medical expenditures the respondents' medical care costs and the cost of drugs. For those 
above age 65, we use the Medicare Current Beneficiary Survey (MCBS). The MEPS is known to under-predict expenditures compared to National Health Expenditure Accounts (NHEA) (Sing et al., 2006). We also find that the MCBS under-predicts expenditures from the NHEA. Without adjustment, we seem to under predict payments (by $\$ 59$ billion for Medicare and $\$ 38$ billion for Medicaid). Our cost estimates are based on average expenditures in the Medical Current Beneficiary Survey (MCBS) and total costs in the MCBS are also lower than in the NHEA. The MCBS is known to undercount medical spending by both the Congressional Budget Office and the CMS (Christensen and Wagner, 2000). ${ }^{6}$ Hence, we adjust those numbers to match the NHEA. More detail can be found in the Appendix (section 5, p. 12).

In addition to the individual outcomes, the model predicts revenues and expenditures by the Federal Government, for the age 50+ population. As part of the predicted medical expenditures, we also predict expenditures by source, including those by Medicare and Medicaid. Next, we compute Social Security retirement benefits for those predicted to receive such benefits. Since we have the AIME of both respondent and spouse, we can precisely estimate the distribution of retirement benefits. We account for spouse and survivor benefits. We also compute disability insurance (DI) benefits and Supplemental Security Income (SSI). We compute DB pension income from average pension payments by tenure, last earnings and early and normal retirement ages using Pension Plan characteristics reported by Employers of HRS respondents. Using all these income flows, for the respondent and the spouse (if present), we compute net household income where taxes include Federal, State, City income taxes as well as the Social Security taxes (OASDI and Medicare). More detail is provided in the appendix.

\section{C.2.5 Simulation Methods}

The simulation starts with the existing age 50+ population in the 2004 wave of the HRS. The microsimulation is stochastic, meaning that transitions are randomly drawn from the joint distributions estimated from the HRS. There are two stochastic elements in the model: the simulation of new cohorts and the simulation of transitions. To generate new cohorts, we make use of the estimated joint distribution and use random draws from the

\footnotetext{
${ }^{\mathbf{6}}$ The Congressional Budget Office, for example, inflated MCBS prescription drug spending by 15 percent to produce its official forecast of the cost of Part D.
} 
correlated errors to generate a new cohort. Second, for each respondent in a given year, we calculate transition probabilities. We then draw random numbers to attribute new outcomes. This process is repeated a number of times to ensure independence from any particular sequence of random numbers. We average over 10 replications.

\section{Scenarios and Results}

To estimate the impact of recent trends in obesity and smoking on public-sector assets and liabilities, we simulate the counterfactual scenario in which both obesity and smoking are gradually returned - by 2030 -- to their 1978 levels. We then study trends in public-sector spending and revenues subsequent to this return to baseline.

\section{D.1 Scenarios}

The dramatic rise in obesity and fall in smoking began approximately in the late 1970s. As a result, we simulate the impact of gradually rolling back obesity and smoking to their 1978 levels. In the simulation, incoming cohorts exhibit gradually lower obesity and higher smoking rates, until 1978 levels are finally reached in the year 2030. The rates of changes in prevalence of obesity, diabetes, hypertension, and smoking among aged 47-56 from 1978 to 2004 are shown in Appendix table A.4. Specifically, we consider:

1. Obesity Scenario: Among 51-52 year-olds, the prevalence of obesity, hypertension and diabetes rolled back to 1978 levels (obesity was 13.9\%) by 2030 and then kept constant until 2050.

2. Smoking Scenario: Among 51-52 year-olds, prevalence of current smokers rolled back to 1978 level (37.5\%) and then kept constant until 2050.

Figure 3 presents the prevalence rates we use under different scenarios for the incoming cohorts. Each of these scenarios is compared to our "baseline scenario." This uses the model to project future trends, assuming that current trends are allowed to persist. We document these baseline trends in the Appendix.

Our analysis demonstrates that the continuing rise in obesity and continuing reduction in smoking both lead to greater public spending. In the case of obesity, while sicker cohorts cost less in terms of annuity obligations, those cost reductions occur strictly at the end of life. Moreover, higher health care costs due to greater morbidity 
start to accrue at earlier ages. On the other hand, while the reduction in smoking improves morbidity, it does so only in the years immediately preceding death. The relatively short window of reduced morbidity is insufficient to offset the annuity costs of substantially greater longevity due to smoking reduction.

\section{D.2 Results}

We first discuss results in the baseline scenario and compare our estimates with published government projections to gauge validity. We then compare the results from the baseline with those from the two "roll back" scenarios.

\section{D.2.1 Baseline Estimates and Comparability with Administrative Data}

In Table 3, we present detailed results for the population aged 50+ in 2004, 2030 and 2050. Given current trends, we project the size of the population aged 50+ will increase by nearly $75 \%$ from 80.7 million in 2004 to 144 million in 2050. This result, shown in Table 3, largely reflects the effect of population aging. Reinforcing these effects is the increase in life expectancy from age 50, which is projected to move from 30.9 years in 2004, to 31.6 years in 2050 (Figure 4). However, Figure 4 also documents an expected decline in the number of years of healthy living (without disability) from 25.2 to 24.75 for this group. In other words, the increase in life expectancy comes entirely from longer time spent disabled or in an unhealthy state. The prevalence of obesity among the $50+$ is projected to increase from $28.1 \%$ in 2004 to $48 \%$ in 2050. As a result, the prevalence of diabetes, hypertension, and heart disease are also projected to increase. In 2050, 28.4\% of Americans are projected to have diabetes and nearly two-thirds to have hypertension.

As shown in Figure 5, our population forecast (last bar) for the age 65+ population in 2050 is very similar to that of the Social Security administration (80.3 vs. 80.8 million) and much lower than Census projections (86.7), which assume larger reductions in mortality.

Turning to economic outcomes, we project a decline in labor force participation among the $50+(42.2 \%$ in 2050 compared to $48.7 \%$ in 2004). For the most part, this is due to changing demographics in the U.S. population (more Hispanics and blacks, more female), which also explains the decline in average earnings. 
Government revenues are projected to increase from 2004 to 2050, primarily due to population growth. Government entitlement expenditures are also projected to increase substantially over the next 40 years. For example, Medicare costs are projected to be more than 2.5 times higher in 2050 than in 2004 ( $\$ 731.9$ billion in 2050) while OASI expenditures are projected to be three times higher (\$1.304 trillion in 2050). Since all simulations are performed in 2004 dollars and do not make assumptions about inflation, growth and cost-of-living adjustments, it is difficult to compare these forecasts to other published estimates. However, the real growth in costs more accurately reflects the size of these changes in terms of current purchasing power.

Figure 6 compares our estimates of total costs in 2004 with other published sources. Revenues appear in the top panel against expenditures in the bottom panel. To estimate total taxes paid by age, we employ a two-step strategy. We first compute the total across all age groups from published sources. Using the Current Population Survey (CPS) of 2004, we then compute taxes paid using TAXSIM, and then compute the share of taxes paid by the age 50+. We use these two numbers to compute taxes paid for 2004 among the 50+, which yields $\$ 307$ billion. In the simulation, we censor incomes at $\$ 200 \mathrm{k}$, due to the scarcity of observations above this threshold. According to the Tax Policy Center, those earning above 200k paid nearly 32\% of all federal taxes in 2001. Hence, this gives a total tax paid by the age $50+$ of $\$ 205.4$ billion, which is within $5 \%$ of our estimate of $\$ 216.5$ billion. Our estimate of Social Security payroll taxes is similarly close.

For expenditures, the bottom panel of Figure 6 shows that we do a good job of matching total OASI benefits paid (we predict $\$ 417.2$ billion compared to $\$ 408.5$ billion from SSA publications), disability and SSI payments. For Medicare and Medicaid, we have adjusted payments so they match National Health Expenditure Accounts (NHEA). Overall, the model does a reasonable job matching data from administrative sources. Perhaps more importantly, the results from the baseline scenario make clear the rapidly increasing financial burden on a shrinking workforce. To isolate the role played by trends in health, we now look at a number of counterfactual scenarios. 


\section{D.2.2 Obesity Scenario}

The obesity scenario rolls back the prevalence of obesity among 50 year-olds to its 1978 level by 2030, where it remains until the end of the scenario, in 2050. As shown in Table 4 , this will decrease the prevalence of obesity among the age 50+ in 2050 from $48 \%$ to $24.6 \%$, nearly a $50 \%$ drop.

We also simulate a decrease in the prevalence of associated health conditions. For example, the prevalence of diabetes drops from $28.4 \%$ in the baseline to $18.3 \%$. As a result, the size of the age $65+$ population in 2050 is projected to be higher by roughly 2 million. This is due to an increase in life expectancy as shown in Figure 7, which rises by 2.2 years. The increase in life-expectancy also brings about a decrease in the expected number of years living with a disability. These provide important health benefits to cohorts alive in these years.

In 2050, the obesity reduction scenario implies 3.97\% reduction in Medicare costs, due largely to the better health of the population. Medicaid savings are even larger, $8.6 \%$, due to the higher prevalence of obesity and smoking in the Medicaid population. On the other hand, OASI benefits increase by $\$ 28 \mathrm{bn}$ when we reduce obesity, because of the associated increase in longevity. This offsets nearly half of the Medicare/Medicaid savings. On the other hand, revenues increase slightly, in part due to longevity. Federal income tax revenue increases by $2.34 \%$ in 2050 or $\$ 5.9$ billion.

To grasp the importance of these differences, we computed the present value of the gains and losses for each group of expenditures from 2004-2050. We used a 3\% real discount rate. We present these estimates in Figure 8. The present value of all Medicare and Medicaid savings under the obesity scenario are $\$ 199.5$ billion and $\$ 166.1$ billion respectively. In 2004, total retirement payroll tax paid by the population aged 50+ was $\$ 73.8$ billion. This represents roughly five years' worth of employee payroll tax contributions. The present value of future additional Social Security benefit outlays is $\$ 104.8$ billion. The costs to Social Security are smaller than the benefits to Medicare in part because they occur farther in the future. As new, healthier (and lighter) cohorts enter the model, the disability reduction benefiting Medicare takes place before the increase in longevity that hurts Social Security. On the revenue side, rolling back obesity leads to a boost of $\$ 59.3$ billion (adding Federal tax, OASI and Medicare Tax). When added to the 
expenditure savings, the total net effect of obesity reduction on public finances is $\$ 340.9$ billion in savings. Our analysis suggests that the health benefits of lower obesity occur earlier than the (public finance) costs of greater longevity.

\section{D.2.3 Smoking Scenario}

We now turn our attention to shifts in the prevalence of smoking. Under the baseline scenario, the prevalence of smoking (ever smoked and currently smoking) is projected to go down in the future. The "roll back" scenario gradually reduces the prevalence of smoking to its 1978 level, by 2030. We assume that, in the future, entering cohorts of 50-54 year-olds will smoke more than today's 50-54 year-olds. The extent of that change is shown in Figure (bottom panel).

Table 5 reports detailed results of this simulation. The size of the population age $65+$ in 2050 is 3.74 million smaller under this scenario. However, as shown in the table, this gain occurs mostly after 2030; the timing is driven by the long delayed effect of smoking on longevity. Inspecting Figure 9, life expectancy at age 50 is 2.45 years lower than under the baseline in 2050. This translates into cost savings for OASI but surprisingly also for Medicare and Medicaid. This is due to the reduction in the size of the elderly population, which offsets the other health effects. Greater mortality costs the government a $3.65 \%$ decline in Federal taxes, or $\$ 9.1$ billion. Hence, while expenditures decrease, so do revenues.

In Figure 10, we report the effect of the smoking scenario on the present value of various government expenditures. Apart from disability insurance, the effect is negative. For DI, the positive effect can be traced back to our transition model. The estimation of entrance into DI yielded modest positive effects for having cancer, lung disease and ever smoked. These in turn lead to higher take up of disability benefits. Hence, unlike the obesity scenarios, this scenario yields very modest effects on government expenditures but large effects on life expectancy. The longevity effect offsets to a large extent the increase in disability and health care costs. The total expenditure effect is $\$ 176.3$ billion. On the revenue side, there is a large negative effect on revenues ( $\$ 118.3$ billion). The bulk of this effect is on Federal tax revenue. Overall, the net public sector savings is $\$ 58$ billion which is much smaller than the net public sector effect of the obesity roll back 
scenario. While smoking improvements have very different health consequences than obesity increases, they both increase public-sector financial liabilities.

\section{D.2.4 Comparison of Results to Existing Estimates}

\section{Smoking}

To assess the plausibility of our results, we first compared our estimates of the difference in life expectancy for obese/non-obese and smokers/non-smokers with other published estimates. We used the 2004 cohort of respondents aged 51/52. For comparison purposes, we do not condition on other characteristics that might differ across groups. Table 6 demonstrates that 50 year-old current smokers had a remaining life expectancy of 25.8 years. Former smokers can expect to live 6.1 additional years, while those who never smoked can expect an additional 3.1 years. We compared those estimates with others in the literature (Rogers and Powell-Griner, 1991). For females (males), Rogers and Powell-Griner estimated that, compared to current smokers, former smokers could expect to live 3.7 (5.2) additional years and those who never smoked an additional 2.4 (1) years. Hence, the difference in life-expectancy between non-smokers and current smokers at age 50-54 ranged from 6.2 to 6.6 years. ${ }^{7}$ Our estimated difference of 9.2 years is somewhat higher. Particularly, we estimate larger mortality rate differences for older age groups.

This difference can be best explained by mortality selection. Rogers and PowellGriner computed period life-tables, using current smoking status. This compares unconditional mortality rates across surviving smokers and surviving non-smokers. On the other hand, we condition on initial smoking status at age 50, and we used longitudinal data to model selection on observable characteristics. When we computed unconditional

\footnotetext{
${ }^{7}$ Sloan et al. (2004) estimate life tables for lifetime smokers, typical smokers and non-smokers
} using the HRS. Lifetime smokers are defined as smokers who are never predicted to quit while typical smokers are smokers who eventually quit at some age. Hence, Sloan et al.'s estimates are not directly comparable to ours. They estimate that a 50 year old male (female) lifetime smoker has 23 (27.7) remaining life years, a typical smoker 25.8 (29.9) years and a non-smoker 31.1 (33.6) years. Hence, the differences are of somewhat smaller than those we simulated. Furthermore, the authors consider the counterfactual in which existing smokers quit smokers (and vice-versa) while the comparison here is between non-smokers and smokers. When we turn smokers into non-smokers into our simulations, we get a 7.7 years improvement in life expectancy which is closer to the Sloan et al. estimates. 
mortality rates by current smoking status in the HRS - the approach most closely resembling Rogers and Powell-Griner -- we found the same magnitudes and patterns they did. Those who continue to smoke after age 50 are likely to be more robust; this unobserved robustness may explain the compression of life expectancy between current smokers and current non-smokers.

\section{Obesity}

We estimate that an obese 50 year-old individual can expect to live 2.3 fewer years compared to a non-obese individual. There is much debate in the literature over the effect of obesity on life expectancy (Calle et al., 1999; Grabowski and Ellis, 2001; Peeters et al., 2003). Studies focusing on young, middle-aged, or near-elderly populations tend to find obesity reduces longevity. For instance, Peeters Barendregt et al., using data from the Framingham Heart Study, show that 40 year-old females nonsmokers lost 3.3 years (males lost 3.1 years) because of obesity. However, there is evidence that, among older age groups, obesity may be protective (Grabowski and Ellis, 2001). However, when starting the comparison at age 70, mortality selection may be a problem. The surviving obese and non-obese populations are likely to be differentially selected such that unobserved frailty confounds the relationship between obesity and future mortality.

\section{E. Discussion}

In this paper, we exploit a health microsimulation model, outfitted with economic outcomes, to study the public finance consequences of trends in health. It is well understood that better health leads to cost-savings for public health insurance, but greater liabilities for public annuities. However, the timing and duration of mortality and morbidity changes are of crucial importance. By definition, medical cost savings accrue earlier in life than increases in annuity burden. This helps explain why the rising rate of obesity leads to greater public liabilities; a result that is aided further by the modest longevity reductions associated with obesity. However, this tendency may not be enough if - as in the case of smoking reduction - the period of reduced morbidity is relatively short and close to the end of life. 
There is a popular perception that government programs benefit from worsened health. This perception is typically formed from the case of smoking, in which longevityreductions do in fact benefit a number of government programs. However, this intuition breaks down in a number of prominent and instructive examples. For example, lowering obesity would save Medicare and Medicaid more than it would cost in terms of public annuity obligations. Public health interventions in these areas, therefore, could produce very large gross returns for the public purse.

From a positive point of view, trends in health among the young create something of a "perfect storm" for public spending. While obesity growth and smoking reductions would appear to work at cross-purposes, they both add fuel to the growing public debt burden in the US. We simulated the joint scenario, in which both obesity and smoking are rolled back to their 1978 levels and found this would shave $\$ 429.5$ billion off publicsector liabilities, from 2004 to $2050{ }^{8}$ This is primarily due to lower public health care expenditure liabilities, which in turn is driven mostly by the morbidity effects of rising obesity. The reduction in Social Security expenditures due to these combined trends is relatively small, around $\$ 17.5$ billion.

From the broadest possible perspective, the total additional liability of $\$ 429.5$ billion adds a bit less than $5 \%$ to the roughly $\$ 10.8$ trillion (and rising) national debt currently outstanding. While this is not trivial, it would be prima facie unrealistic to argue that trends in two health behaviors have played a dominant role in America's current fiscal predicament. More importantly, trends in obesity and smoking have placed further pressure on public health care programs straining under the weight of both demographics and medical technology. For instance, annual Medicaid costs have spiked by more than $10 \%$ as a result of the combined trends in obesity and smoking, while annual Medicare costs have risen by 6.5\%. Moreover, the effects are also large relative to the size of the population treated. Each newly obese individual will add $\$ 8,338$ to Medicare over his lifetime (after age 50), while each fewer smoker adds $\$ 20,563$. At the margin, therefore, trends in public health involve relatively large stakes for public finances, and particularly for the Medicaid program.

\footnotetext{
${ }^{8}$ The detailed results for this scenario appear in the appendix tables.
} 
To be clear, our study is not designed to calculate the total social welfare effects of changing public health trends, but rather to isolate the public finance effects, which are of independent interest to policymakers. As such, we cannot justifiably advocate increases in smoking, or even reductions in obesity, upon the basis of these results alone. However, our work demonstrates that the public finance effects of these two major health trends are large enough to become part of the social welfare calculus for evaluating changes in these two health behaviors. 


\section{References}

Adams, P., M. D. Hurd, D. McFadden, et al. (2003). "Healthy, wealthy, and wise? Tests for direct causal paths between health and socioeconomic status." Journal of Econometrics 112(1): 3-56.

Banks, J., M. Marmot, Z. Oldfield, et al. (2006). "Disease and Disadvantage in the United States and in England." JAMA 295(17): 2037-2045.

Bhattacharya, J., D. Cutler, D. P. Goldman, et al. (2004). Disability Forecasts and Future Medicare Costs. Frontiers in Health Policy Research. D. Cutler, and A. M. Garber, Eds. Cambridge, MA, MIT Press. 7.

Bonneux, L., J. J. Barendregt, K. Meeter, et al. (1994). "Estimating clinical morbidity due to ischemic heart disease and congestive heart failure: the future rise of heart failure." Am J Public Health 84(1): 20-8.

Calle, E. E., M. J. Thun, J. M. Petrelli, et al. (1999). "Body-Mass Index and Mortality in a Prospective Cohort of U.S. Adults." N Engl J Med 341(15): 1097-1105.

Christensen, S. and J. Wagner (2000). "The costs of a Medicare prescription drug benefit." Health Aff 19(2): 212-218.

French, E. (2005). "The Effects of Health, Wealth, and Wages on Labour Supply and Retirement Behaviour." Review of Economic Studies 72(2): 395-427.

Goldman, D., M. Hurd, P. Shekelle, et al. (2004). "Health status and medical treatment of the future elderly: Final Report." RAND Corporation Technical Report TR-169. Santa Monica, CA.

Goldman, D. P., B. Shang, J. Bhattacharya, et al. (2005). "Consequences of health trends and medical innovation for the future elderly." Health Aff (Millwood) 24 Suppl 2: W5R5-17.

Grabowski, D. C. and J. E. Ellis (2001). "High body mass index does not predict mortality in older people: analysis of the Longitudinal Study of Aging." Journal of American Geriatrics Society 49(7): 968-79.

Hayward, M. D. and D. F. Warner (2005). Demography of Population Health. The Handbook of Demography. D. L. Poston Jr, and M. Micklin, Eds. New York, Springer: 809-825.

Hurd, M., H. Hoynes and H. Chand (1998). Household Wealth of the Elderly under Alternative Imputation Procedures. Inquiries in the Economics of Aging. D. Wise, Ed. Chicago, University of Chicago Press: 229-257.

Lakdawalla, D. N., D. P. Goldman and B. Shang (2005). "The health and cost consequences of obesity among the future elderly." Health Aff (Millwood) 24 Suppl 2: W5R30-41.

Lee, R. D. (2000). "The Lee-Carter Method for Forecasting Mortality, With Various Extensions and Applications." North American Actuarial Journal 4: 80-91.

MacKinnon, J. G. and L. Magee (1990). "Transforming the Dependent Variable in Regression Models." International Economic Review 31(2): 315-339.

Manton, K., B. Singer and R. Suzman (1993). Forecasting the Health of Elderly Populations. New York, Springer-Verlag.

Michaud, P.-C., A. Kapteyn, J. P. Smith, et al. (2006). "The Effects of Attrition and NonResponse in the Health and Retirement Study." Santa Monica, CA. 
Michaud, P.-C. and A. van Soest (2008). "Health and wealth of elderly couples: Causality tests using dynamic panel data models." Journal of Health Economics 27(5): 1312-1325.

Michaud, P.-C., A. van Soest and T. Andreyeva (2007). "Cross-Country Variation in Obesity Patterns among Older Americans and Europeans." Forum for Health Economics \& Policy (Aging and Medical Care Costs) 10(2).

Mokdad, A. H., B. A. Bowman, E. S. Ford, et al. (2001). "The continuing epidemics of obesity and diabetes in the United States." Journal of the American Medical Association 286(10): 1195-200.

Oharra, J., J. Sabelhaus and M. Simpson (2004). "Overview of the Congressional Budget Office Long-Term (CBOLT) Policy Simulation Model." Congressional Budget Office. Washington DC.

Peeters, A., J. J. Barendregt, F. Willekens, et al. (2003). "Obesity in Adulthood and Its Consequences for Life Expectancy: A Life-Table Analysis." Ann Intern Med 138(1): 24-32.

Rogers, R. G. and E. Powell-Griner (1991). "Life Expectancies of Cigarette Smokers and Nonsmokers in the United States." Social Science and Medicine 32(10): 1151-9.

Ruhm, C. ( 2007). "Current and Future Prevalence of Obesity and Severe Obesity in the United States." Forum for Health Economics \& Policy 10(2).

Rust, J. and C. Phelan (1997). "How Social Security and Medicare Affect Retirement Behavior In a World of Incomplete Markets." Econometrica 65(4): 781-831.

Sullivan, D. F. (1971). "A single index of mortality and morbidity." HSMHA Health Reports 86(4): 347-354.

Toder, E., L. Thomson, M. Favreault, et al. (2002). "Modeling Income in the Near Term: Revised Projections of Retirement Income Through 2020 for the 1931-1960 Birth Cohorts." Urban Institute Report to SSA. Washington, D.C. 


\section{Figure 1}

\section{U.S. Trends in Selected Health Outcomes}

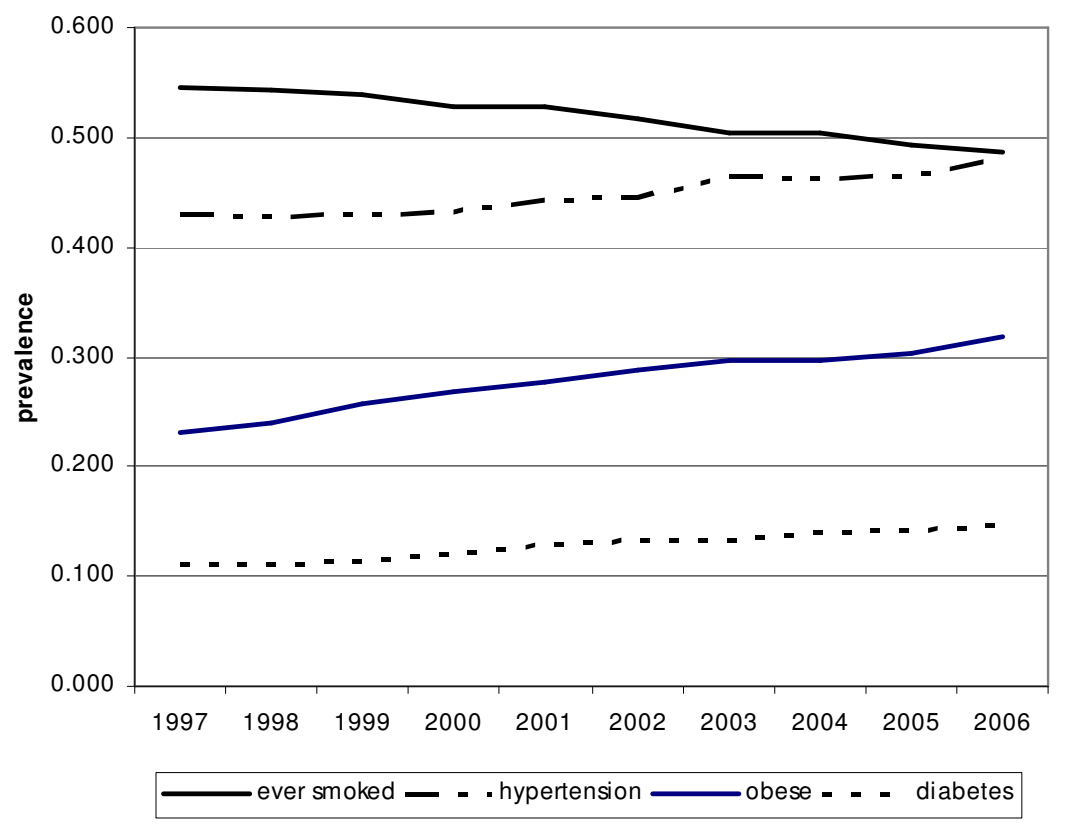

Source: National Health Interview Surveys (NHIS) 1997-2006, age 50+ population. 
Figure 2

\section{Overview of the Future Elderly Model}

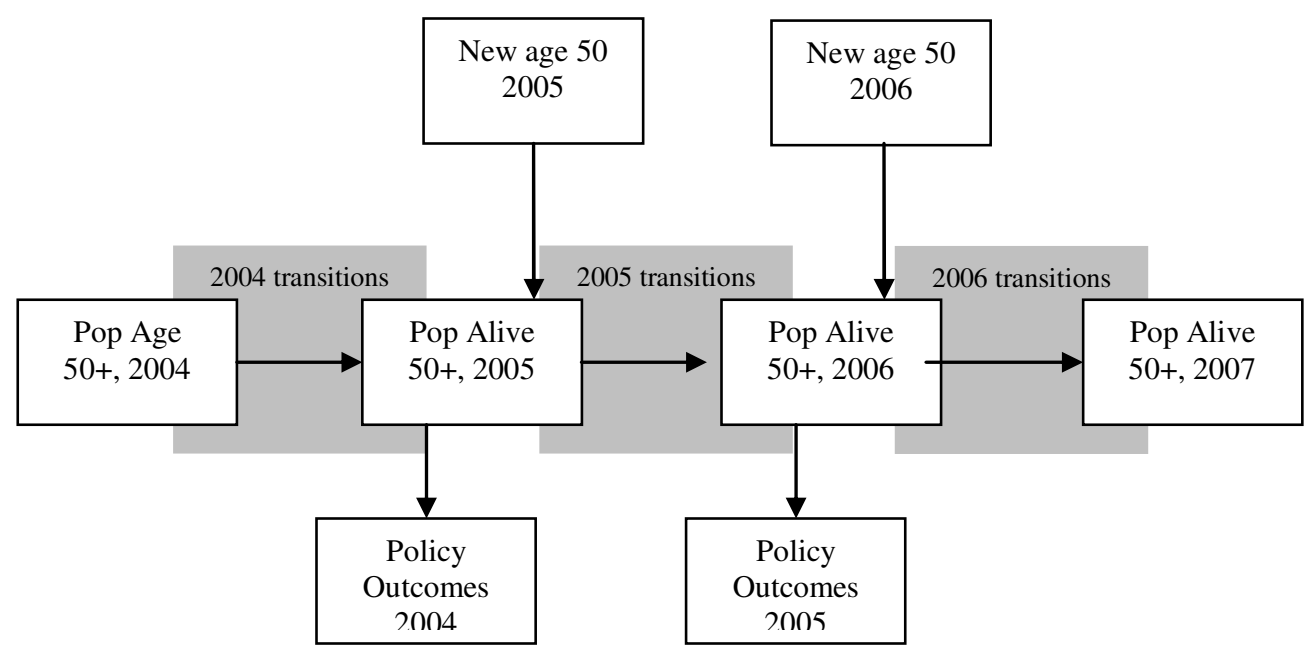




\section{Figure 3}

Obesity Scenario (\% with BMI $>30$ at age 50)

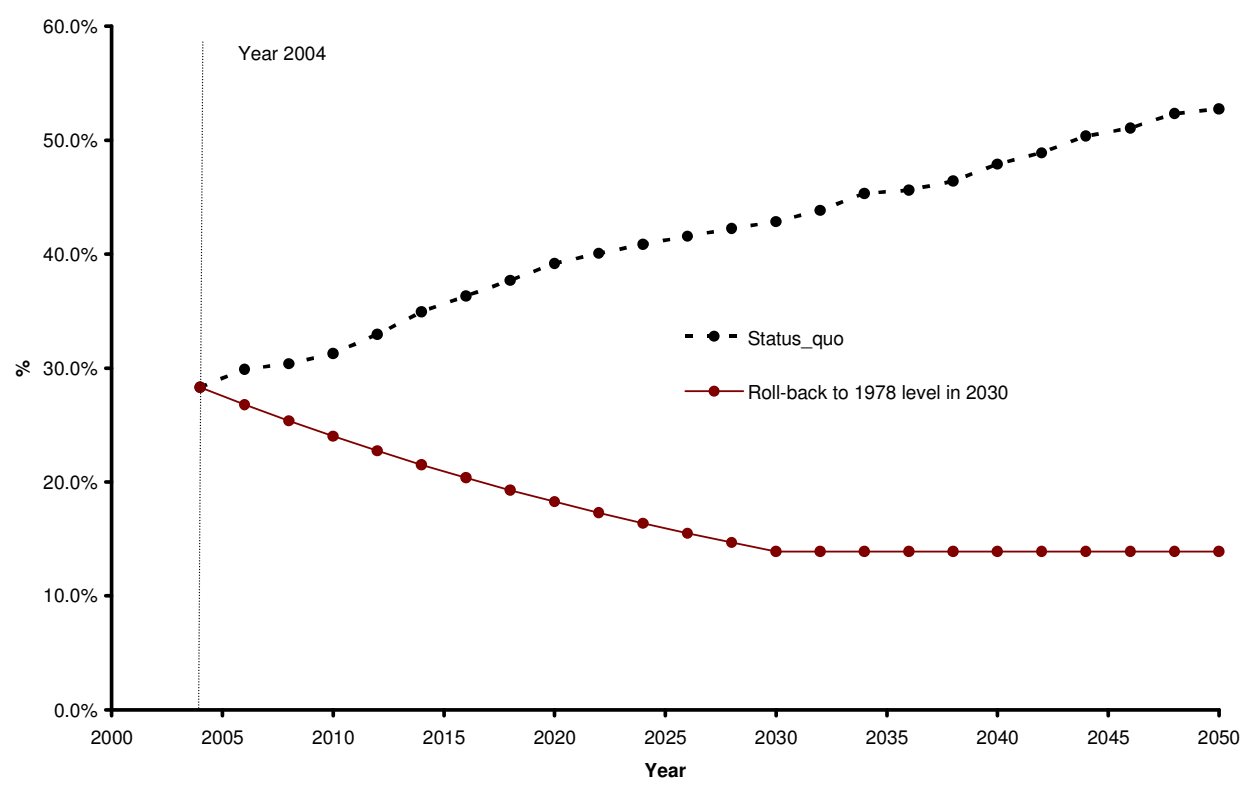

Smoking Scenario (\% Current Smokers at age 50)

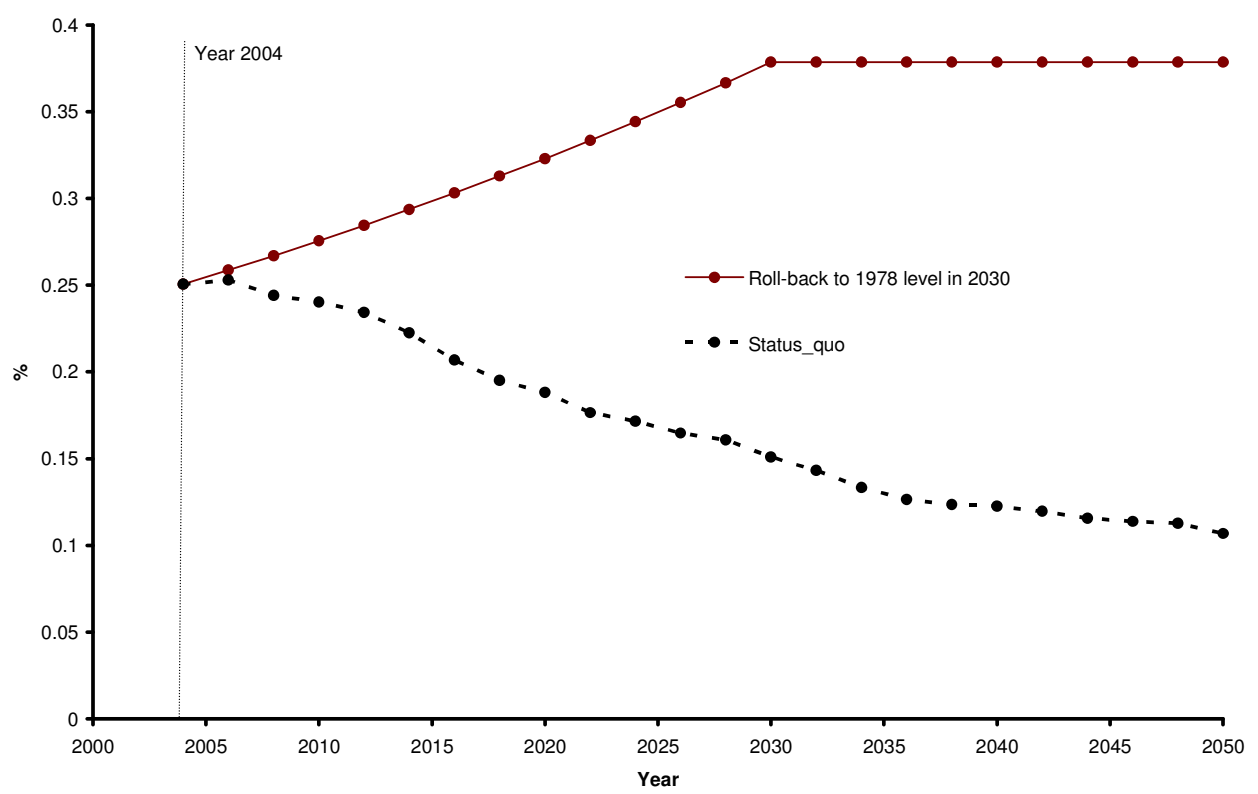

Source: NHANES and projections from existing studies. See Technical Appendix. 


\section{Figure 4}

Baseline Projection of Life-Expectancy at age $\mathbf{5 0}$ 2004-2050

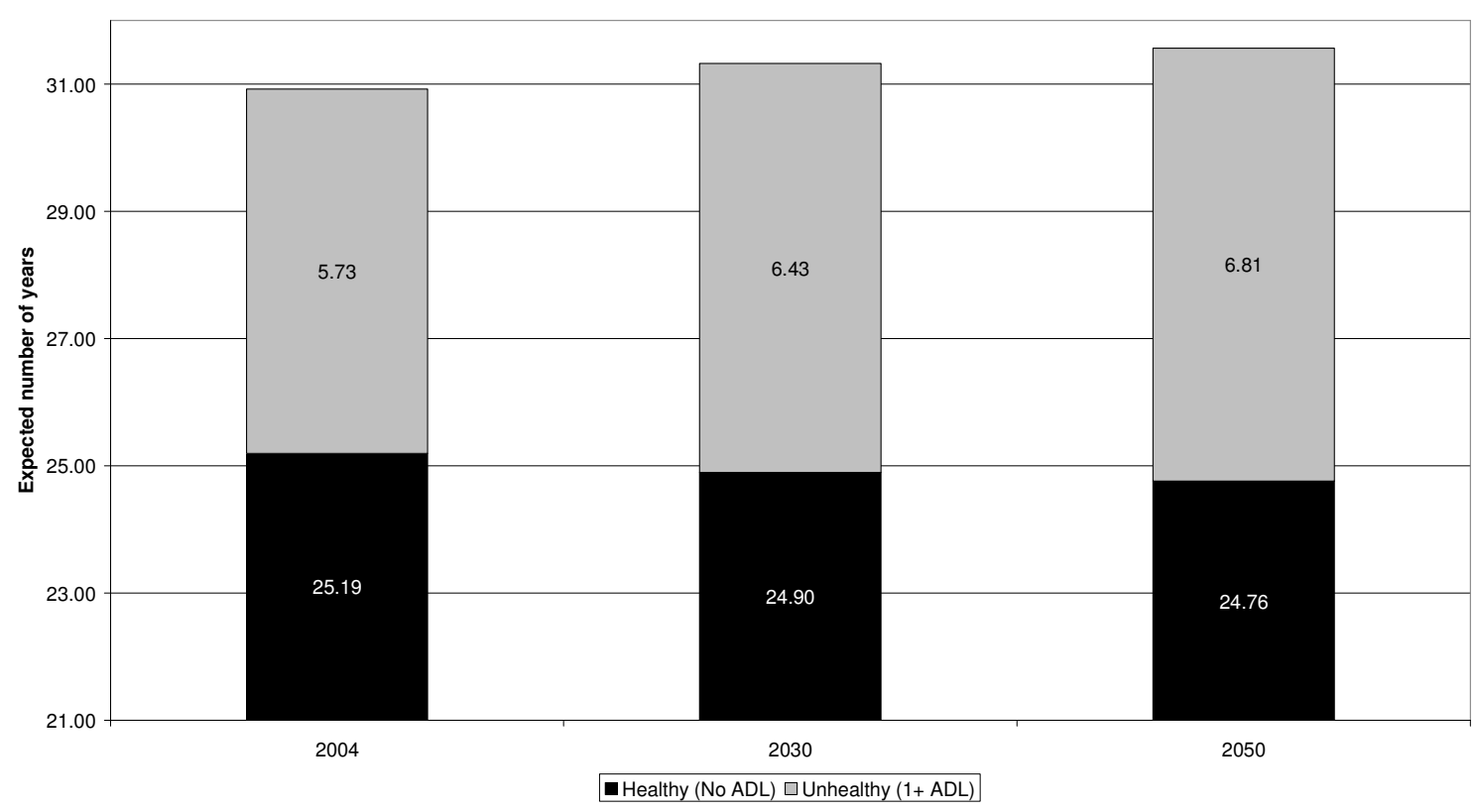


Figure 5

Comparison of Age 65+ Population Forecasts in 2050

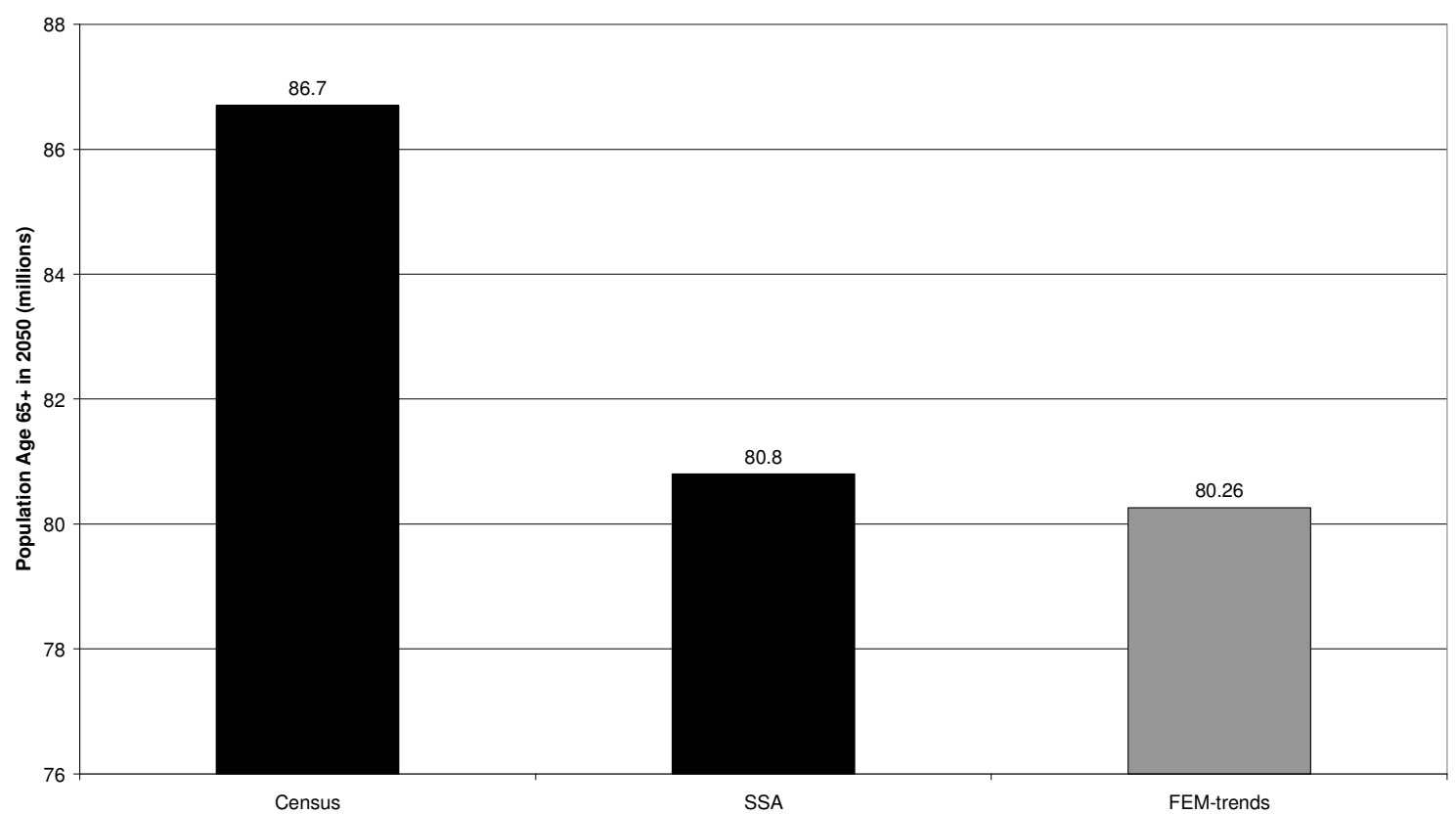

Source: Census, SSA 2008 Annual Report of the Board of Trustees and own Calculations for FEM. 


\section{Figure 6}

Comparison of Government Revenues in 2004: FEM vs. Official Source

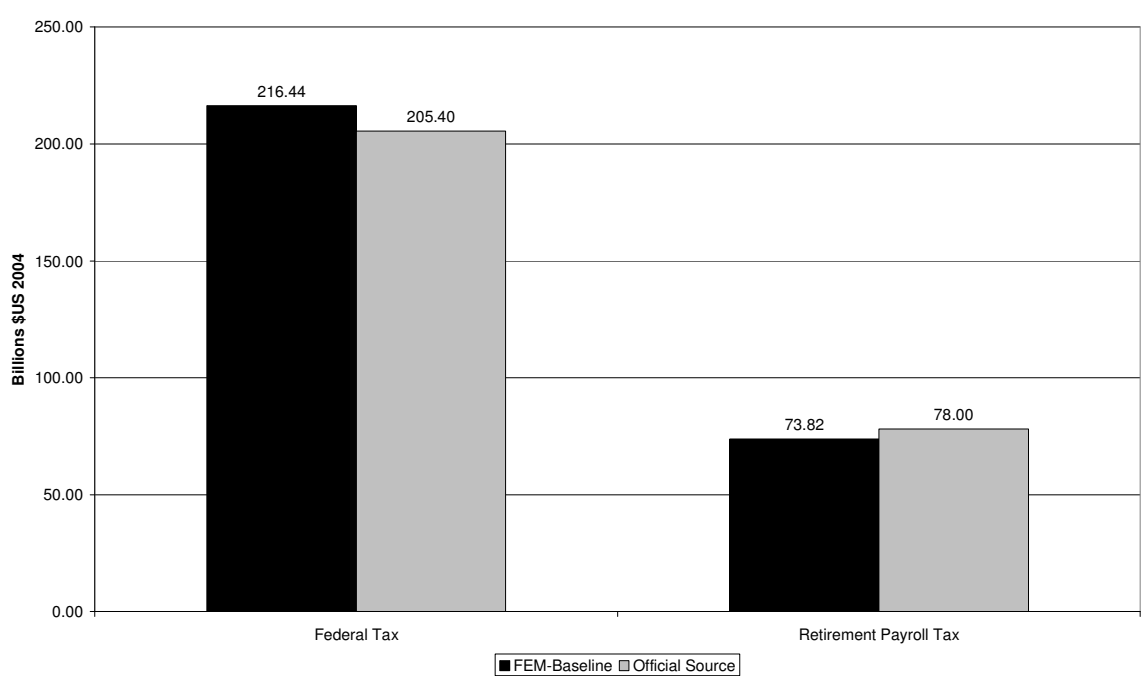

Comparison of Government Expenditures in 2004: FEM vs. Official Source

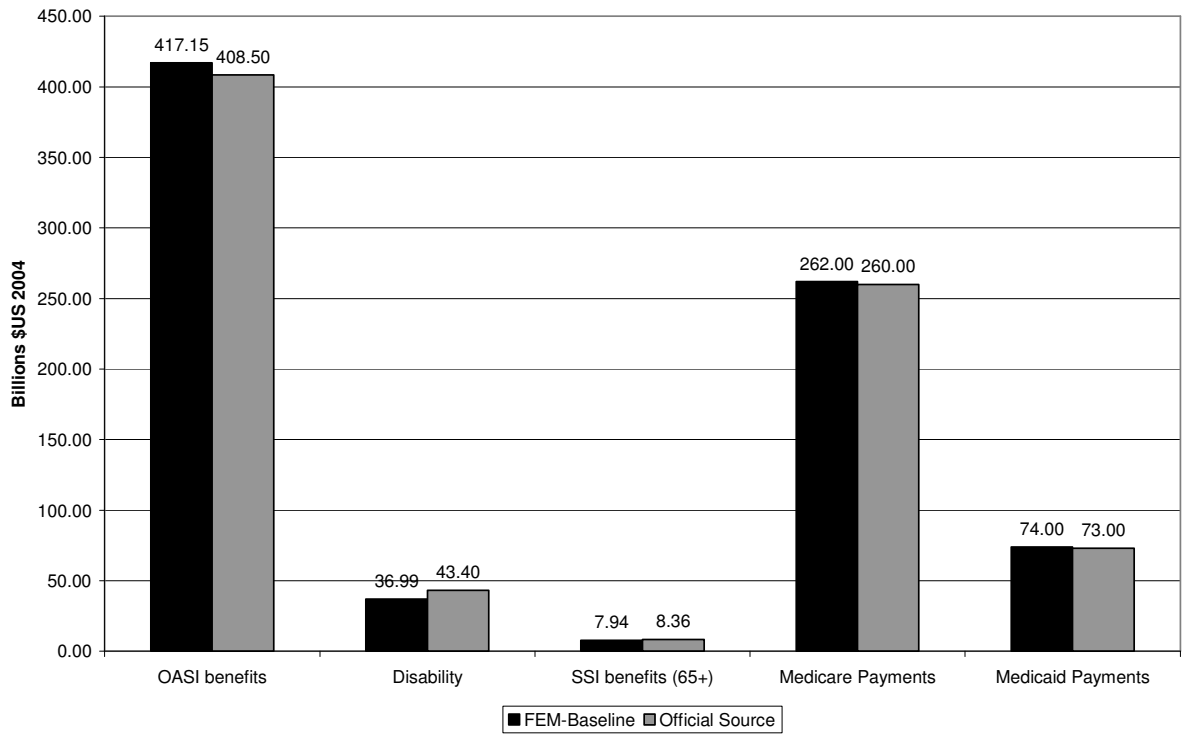

Notes: The total federal individual income taxes in 2004 was $\$ 765$ billion, according to Budget database (Table 2.1. RECEIPTS BY SOURCE: 1934-2009, http://www.gpoaccess.gov/usbudget/fy05/sheets/hist02z1.xls); according to Current

Population Survey, march supplement, 2005, the proportion of federal individual income taxes contributed by aged 51 and older was $40 \%$. As detailed in text, we adjusted this amount for taxes coming from incomes above 200k. The total employment contribution to OASDI trust fund in 2004 was \$554 billion, according to 2005 OASDI Trustees Report; according to Current Population Survey, march supplement, 2005, the proportion of retirement payroll taxes paid by aged 51 and older was $28.3 \%$. OASI includes benefits for: 1) retired workers, 2) Spouses of retired workers, 3) Widow(er)s. It does not include benefits for: 1) Widowed mothers and fathers, 2) Parents of deceased workers; 3) Children of retired workers, 4) Children of deceased workers. 
Figure 7

Life Expectancy at age 50 in Obesity Scenario Relative to Baseline for Cohort Entering in 2050

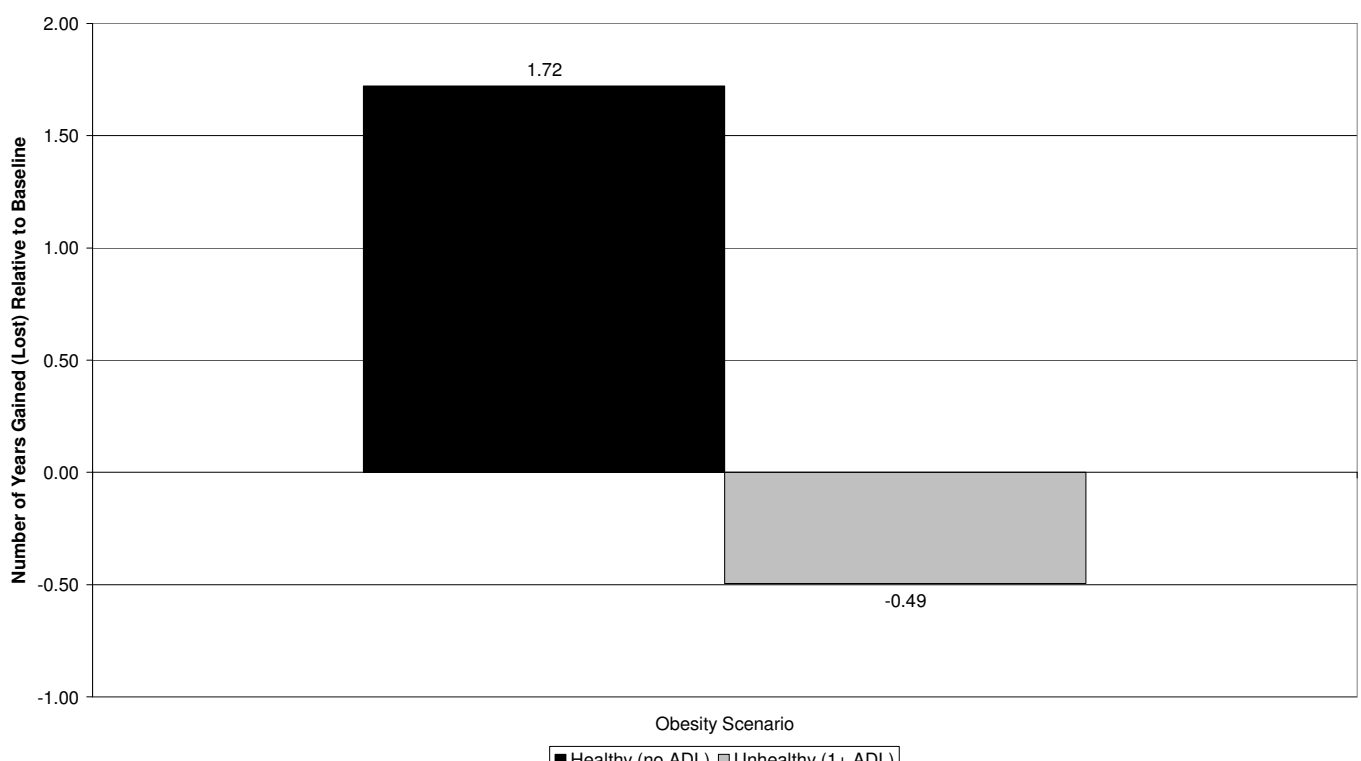

- Healthy (no ADL) $\square$ Unhealthy (1+ADL) 


\section{Figure 8}

Effect of Obesity Scenario on the the Present Discounted Value of Government Expenditures (2004-2050)

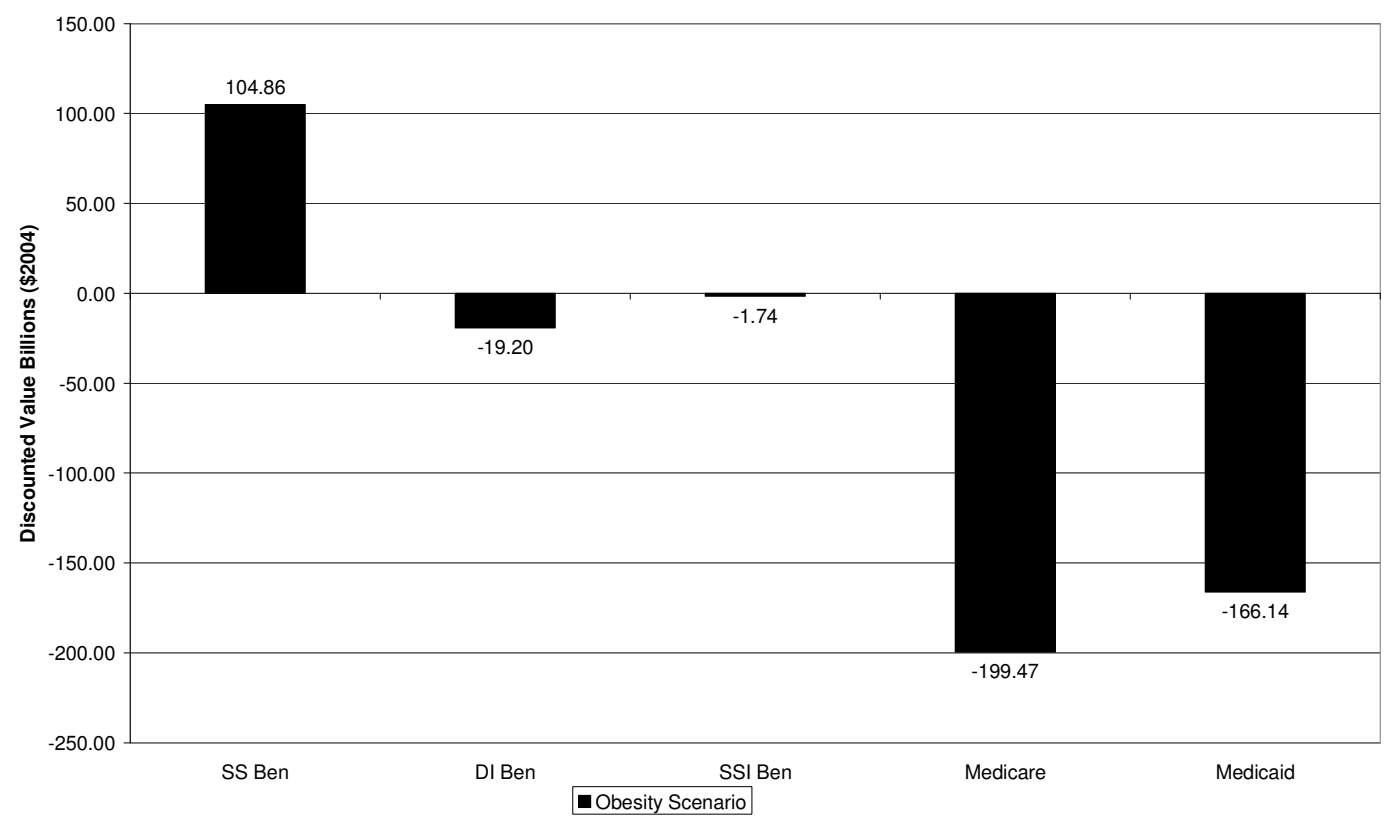


Figure 9

Life Expectancy at age $\mathbf{5 0}$ in Smoking Scenario Relative to Baseline for cohort entering in 2050

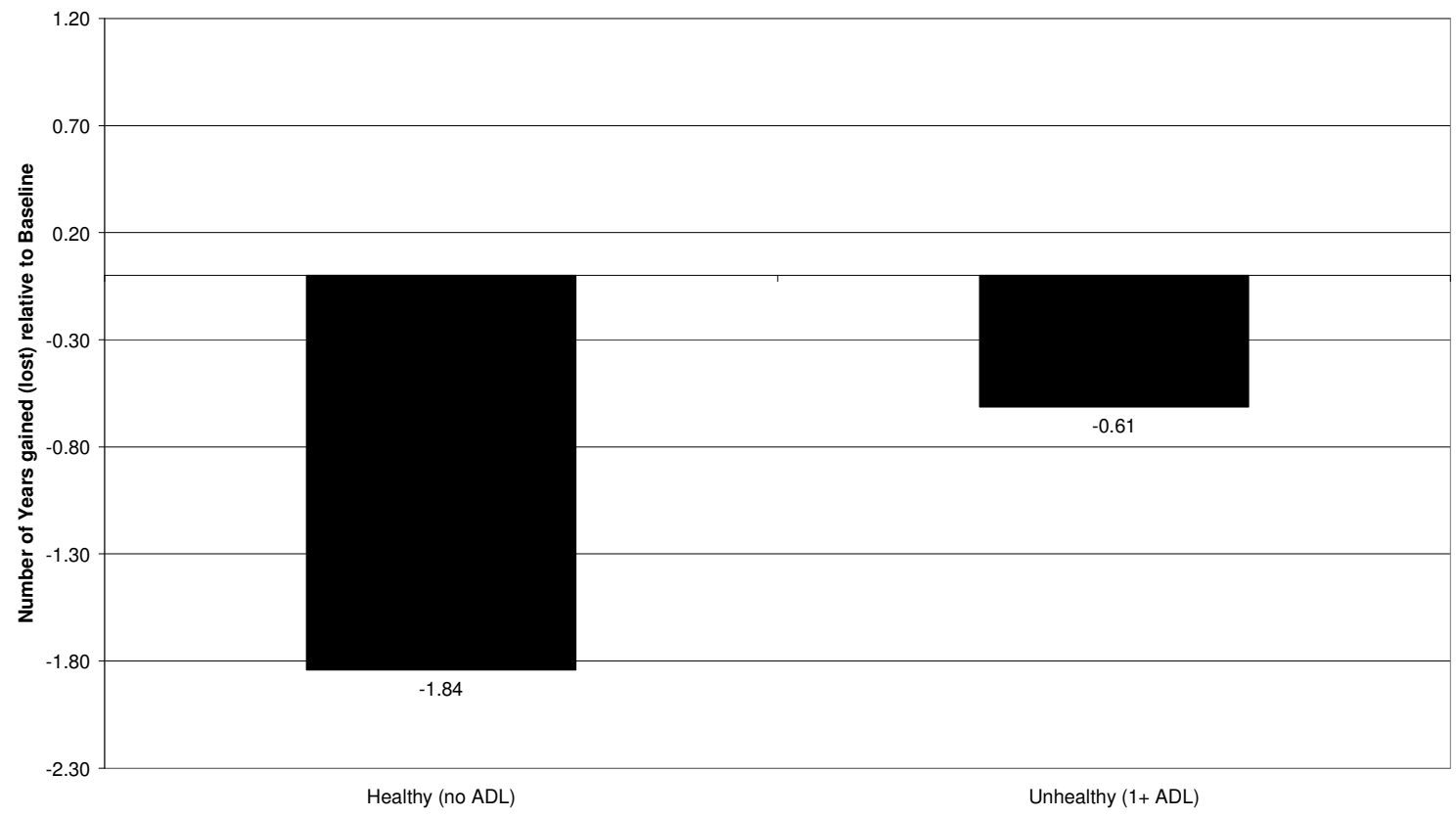


Figure 10

Effect of Smoking Scenario on the the Present Discounted Value of Government Expenditures (2004-2050)

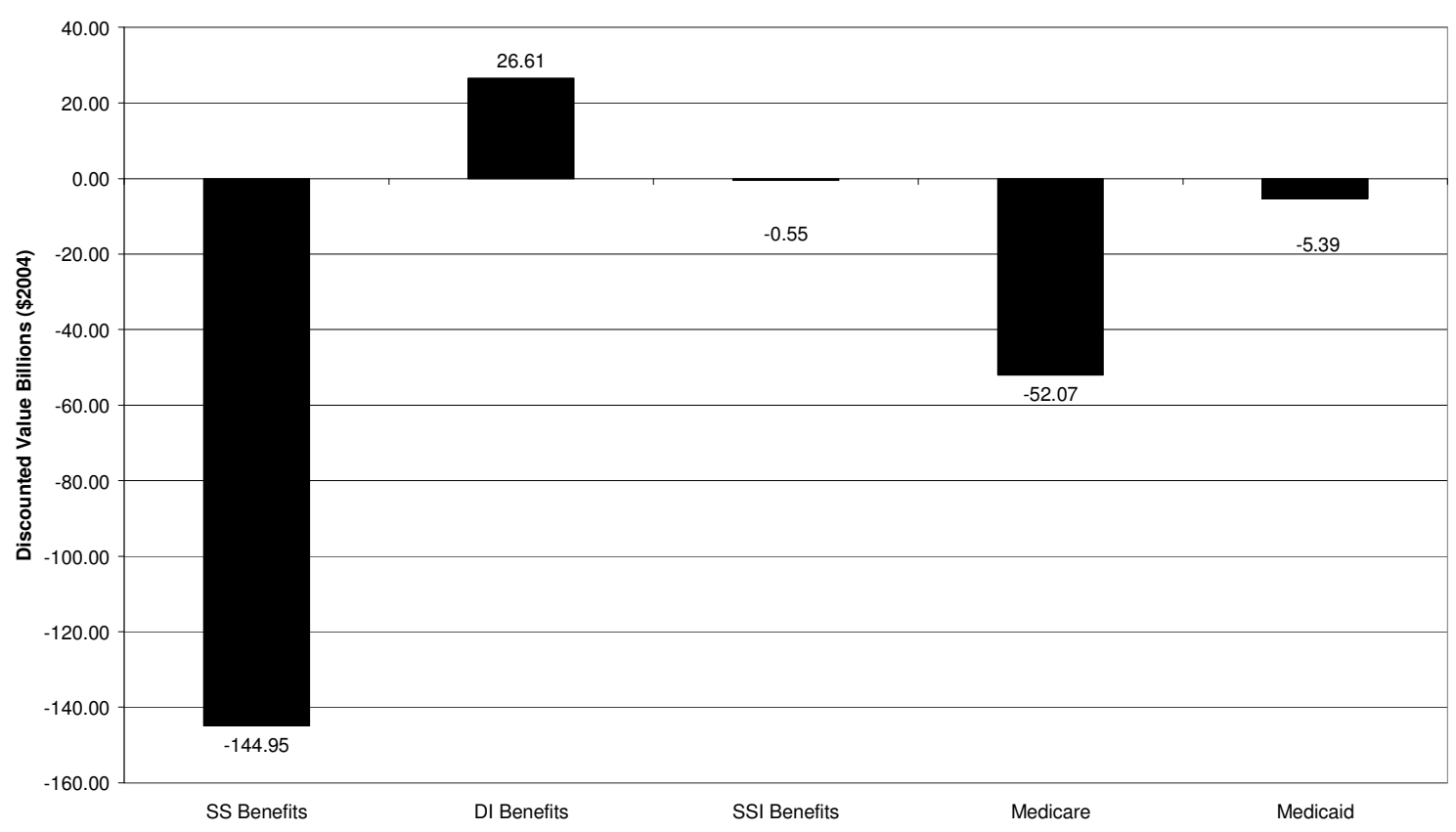




\section{Figure 11}

Projection of Government Expenditures Relative to Baseline - Obesity Scenario

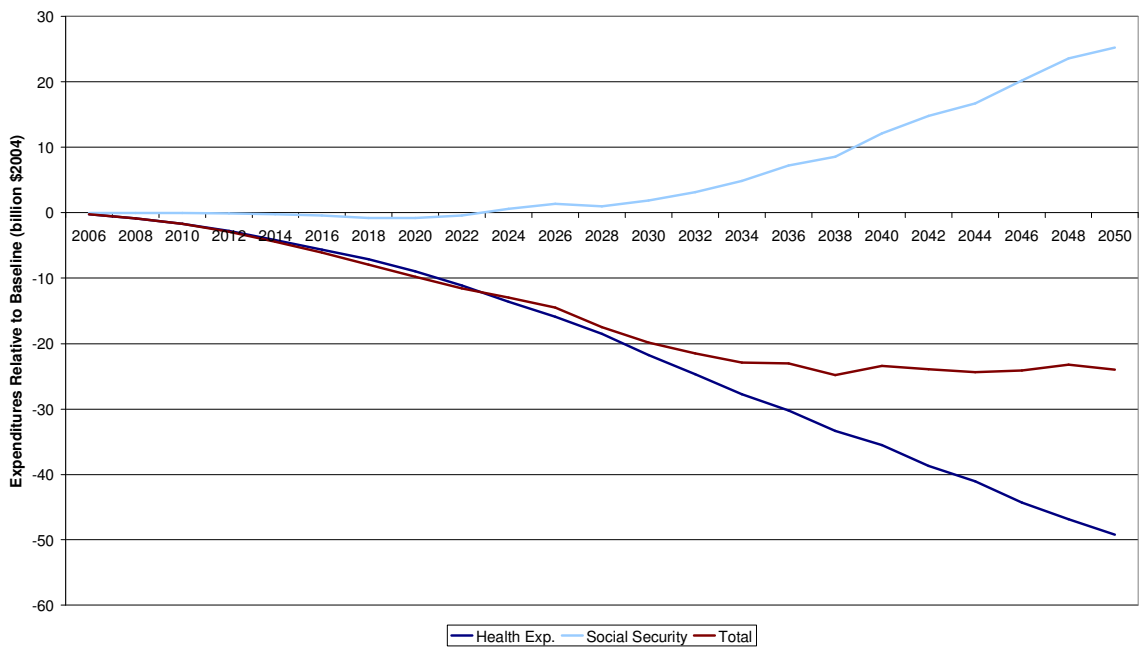

Projection of Government Expenditures Relative to Baseline - Smoking Scenario

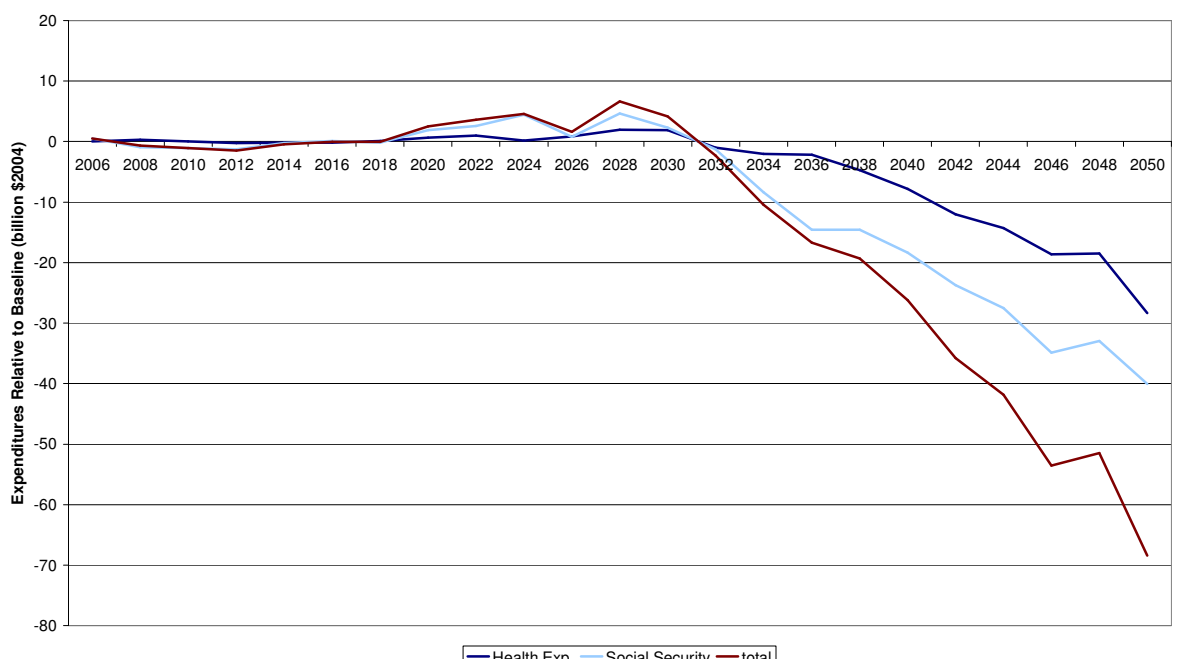

- Health Exp. - Social Security — total 
Table 1

Outcomes in the Transition Model

\begin{tabular}{|c|c|}
\hline Health & SES \& Other \\
\hline $\begin{array}{l}\text { Disease } \\
\text { heart disease } \\
\text { hypertension } \\
\text { stroke } \\
\text { lung disease } \\
\text { cancer } \\
\text { diabetes }\end{array}$ & $\begin{array}{l}\text { LFP \& Benefit Status } \\
\text { working } \\
\text { DB pension receipt } \\
\text { SS benefit receipt } \\
\text { DI benefit receipt } \\
\text { Any Health insurance } \\
\text { ssi receipt }\end{array}$ \\
\hline $\begin{array}{l}\text { Risk factors } \\
\text { Smoking Status } \\
\text { never smoked } \\
\text { ever smoked } \\
\text { current smoker }\end{array}$ & $\begin{array}{l}\text { Financial Resources } \\
\text { financial wealth } \\
\text { earnings } \\
\text { wealth positive }\end{array}$ \\
\hline $\begin{array}{l}\text { BMI Status } \\
\text { normal } \\
\text { overweight } \\
\text { obese } \\
\text { Functional status } \\
\text { No ADL } \\
\text { iADL only } \\
1-2 \text { ADL } \\
3+\text { ADL } \\
\end{array}$ & $\begin{array}{l}\text { nursing home residence } \\
\text { death }\end{array}$ \\
\hline
\end{tabular}

Notes: See Appendix for more details 
Table 2

\section{Outcomes in the Model for New Cohorts}

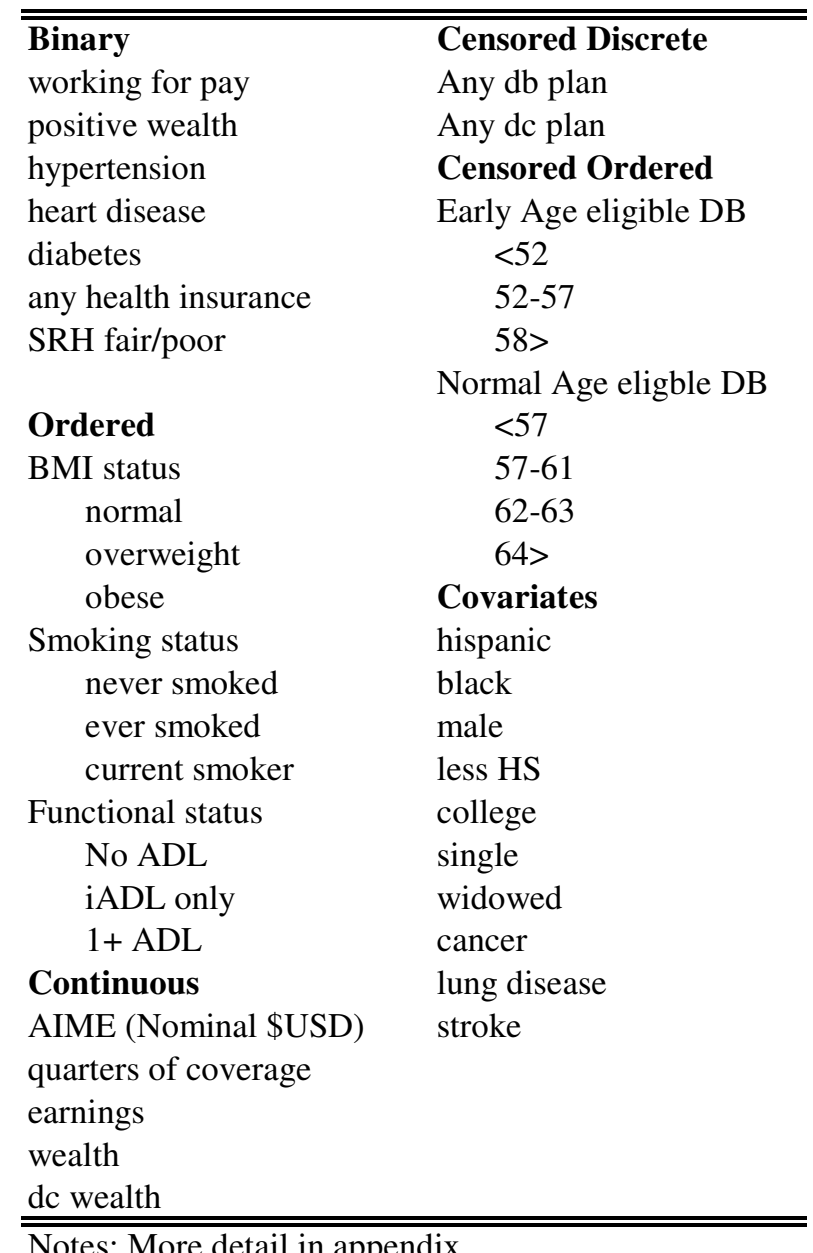

Notes: More detail in appendix. 
Table 3

Baseline Projection of Health and Economic Outcomes for Age 50+ Population 2004-2050

\begin{tabular}{lrrr}
\hline \hline & \multicolumn{3}{c}{ Status Quo Estimates } \\
\hline & 2004 & \multicolumn{2}{c}{ Year } \\
Population size (Million) & 80.71 & 121.91 & 2050 \\
\cline { 2 - 4 } Population 65+ (Million) & 36.25 & 66.64 & 80.26 \\
Prevalence of selected conditions & & & \\
obesity (BMI >=30) (\%) & $28.1 \%$ & $41.7 \%$ & $48.0 \%$ \\
over weight (25<=BMI<30) (\%) & $38.1 \%$ & $38.7 \%$ & $36.4 \%$ \\
Ever-smoked & $58.6 \%$ & $49.6 \%$ & $40.1 \%$ \\
Smoking now & $16.9 \%$ & $9.9 \%$ & $6.8 \%$ \\
Diabetes & $17.0 \%$ & $24.9 \%$ & $28.4 \%$ \\
Heart disease & $23.0 \%$ & $28.3 \%$ & $29.9 \%$ \\
Hypertension & $50.9 \%$ & $61.2 \%$ & $64.8 \%$ \\
Working (\%) & & & \\
Average earnings if working (\$) & $48.7 \%$ & $40.8 \%$ & $42.2 \%$ \\
Labor participation & 42,858 & 37,167 & 37,189 \\
Federal personal income taxes & & & \\
Social security payroll taxes & 216.44 & 224.98 & 250.48 \\
Medicare payroll taxes & 73.82 & 84.26 & 94.71 \\
Government revenues from aged 51+(Billion & 18.67 & 20.33 & 22.85 \\
Government expenditures from aged 51+ & & & \\
(Billion dollars) & & & \\
Old Age and Survivors Insurance & & & \\
benefits (OASI) & & & \\
Disability Insurance benefits (DI) & 317.15 & $1,022.04$ & $1,304.03$ \\
Supplementary Security Income (SSI) & 17.06 & 38.95 & 46.38 \\
Medicare costs & 290.24 & 550.73 & 731.94 \\
Medicaid costs & 118.72 & 154.36 & 234.04 \\
dollars) & 851.05 & $1,418.45$ & $1,827.45$ \\
\hline \hline Notes: All dollars are in 2004 values. & & &
\end{tabular}

Notes: All dollars are in 2004 values. 
Table 4

Detailed Projections of Health and Economic Outcomes for Age 50+ 2004-2050: Obesity Scenario (Roll back to 1978 level by 2030)

\begin{tabular}{|c|c|c|c|c|}
\hline & \multicolumn{2}{|c|}{ Obesity Roll-back } & \multicolumn{2}{|c|}{ Relative } \\
\hline & 2030 & 2050 & 2030 & 2050 \\
\hline Population size (Million) & 122.40 & 146.32 & $0.40 \%$ & $1.61 \%$ \\
\hline Population 65+ (Million) & 66.98 & 82.32 & $0.50 \%$ & $2.57 \%$ \\
\hline \multicolumn{5}{|l|}{ Prevalence of selected conditions } \\
\hline obesity (BMI >=30) (\%) & $29.8 \%$ & $24.6 \%$ & $-28.61 \%$ & $-48.71 \%$ \\
\hline over weight $(25<=\mathrm{BMI}<30)(\%)$ & $40.6 \%$ & $41.5 \%$ & $4.70 \%$ & $13.98 \%$ \\
\hline Ever-smoked & $49.7 \%$ & $40.3 \%$ & $0.15 \%$ & $0.66 \%$ \\
\hline Smoking now & $10.2 \%$ & $7.2 \%$ & $3.33 \%$ & $6.07 \%$ \\
\hline Diabetes & $20.0 \%$ & $18.3 \%$ & $-19.57 \%$ & $-35.73 \%$ \\
\hline Heart disease & $27.6 \%$ & $28.3 \%$ & $-2.20 \%$ & $-5.15 \%$ \\
\hline Hypertension & $57.3 \%$ & $58.2 \%$ & $-6.39 \%$ & $-10.12 \%$ \\
\hline \multicolumn{5}{|l|}{ Labor participation } \\
\hline Working (\%) & $41.0 \%$ & $42.5 \%$ & $0.42 \%$ & $0.83 \%$ \\
\hline Average earnings if working $(\$)$ & 37,231 & 37,282 & $0.17 \%$ & $0.25 \%$ \\
\hline \multicolumn{5}{|c|}{$\begin{array}{l}\text { Government revenues from aged 51+ (Billion } \\
\text { dollars) }\end{array}$} \\
\hline Federal personal income taxes & 227.4 & 256.3 & $1.08 \%$ & $2.34 \%$ \\
\hline Social security payroll taxes & 85.1 & 96.5 & $0.96 \%$ & $1.86 \%$ \\
\hline Medicare payroll taxes & 20.5 & 23.3 & $0.98 \%$ & $1.91 \%$ \\
\hline Total revenue & 333.0 & 376.1 & $1.04 \%$ & $2.19 \%$ \\
\hline \multicolumn{5}{|l|}{$\begin{array}{l}\text { Government expenditures from aged } 51+ \\
\text { (Billion dollars) }\end{array}$} \\
\hline $\begin{array}{l}\text { Old Age and Survivors Insurance benefits } \\
\text { (OASI) }\end{array}$ & $1,025.3$ & $1,332.3$ & $0.32 \%$ & $2.17 \%$ \\
\hline Disability Insurance benefits (DI) & 37.8 & 43.8 & $-3.03 \%$ & $-5.63 \%$ \\
\hline Supplementary Security Income (SSI) & 26.0 & 39.3 & $-0.74 \%$ & $-1.06 \%$ \\
\hline Medicare costs & 538.7 & 702.9 & $-2.19 \%$ & $-3.97 \%$ \\
\hline Medicaid costs & 144.7 & 213.9 & $-6.29 \%$ & $-8.61 \%$ \\
\hline $\begin{array}{l}\text { Medicare }+ \text { Medicaid } \\
\text { T'otal medical costs for aged } 51+(\text { Billion }\end{array}$ & 683.32 & 916.78 & $-3.09 \%$ & $-5.09 \%$ \\
\hline dollars) & 1,380 & 1,748 & $-2.69 \%$ & $-4.34 \%$ \\
\hline
\end{tabular}

Notes: All dollars in 2004 values 
Table 5

Detailed Projections of Health and Economic Outcomes for Age 50+ 2004-2050: Smoking Scenario (Roll back to 1978 level by 2030)

\begin{tabular}{|c|c|c|c|c|}
\hline & \multicolumn{2}{|c|}{ Smoking Scenario } & \multicolumn{2}{|c|}{ Relative } \\
\hline & 2030 & 2050 & 2030 & 2050 \\
\hline Population size (Million) & 121.18 & 139.53 & $-0.60 \%$ & $-3.11 \%$ \\
\hline Population 65+ (Million) & 66.25 & 76.52 & $-0.58 \%$ & $-4.66 \%$ \\
\hline Prevalence of selected conditions & & & & \\
\hline obesity (BMI >=30) (\%) & $41.5 \%$ & $47.8 \%$ & $-0.59 \%$ & $-0.37 \%$ \\
\hline over weight $(25<=\mathrm{BMI}<30)(\%)$ & $38.8 \%$ & $36.6 \%$ & $0.25 \%$ & $0.61 \%$ \\
\hline Ever-smoked & $61.9 \%$ & $66.5 \%$ & $24.72 \%$ & $65.90 \%$ \\
\hline Smoking now & $16.6 \%$ & $18.5 \%$ & $67.21 \%$ & $172.93 \%$ \\
\hline Diabetes & $25.0 \%$ & $28.6 \%$ & $0.38 \%$ & $0.57 \%$ \\
\hline Heart disease & $28.4 \%$ & $30.5 \%$ & $0.61 \%$ & $1.98 \%$ \\
\hline Hypertension & $61.2 \%$ & $64.8 \%$ & $-0.05 \%$ & $-0.06 \%$ \\
\hline Labor participation & & & & \\
\hline Working (\%) & $40.5 \%$ & $41.7 \%$ & $-0.89 \%$ & $-1.08 \%$ \\
\hline Average earnings if working $(\$)$ & 37,091 & 37,131 & $-0.21 \%$ & $-0.15 \%$ \\
\hline $\begin{array}{l}\text { Government revenues from aged 51+ } \\
\text { (Billion dollars) }\end{array}$ & & & & \\
\hline Federal personal income taxes & 220.2 & 241.3 & $-2.14 \%$ & $-3.65 \%$ \\
\hline Social security payroll taxes & 82.6 & 91.4 & $-1.92 \%$ & $-3.46 \%$ \\
\hline Medicare payroll taxes & 19.9 & 22.1 & $-1.99 \%$ & $-3.49 \%$ \\
\hline Total Revenue & 322.7 & 354.8 & $-2.07 \%$ & $-3.59 \%$ \\
\hline $\begin{array}{l}\text { Government expenditures from aged 51+ } \\
\text { (Billion dollars) }\end{array}$ & & & & \\
\hline $\begin{array}{l}\text { Old Age and Survivors Insurance benefits } \\
\text { (OASI) }\end{array}$ & $1,020.3$ & $1,258.9$ & $-0.17 \%$ & $-3.46 \%$ \\
\hline Disability Insurance benefits (DI) & 43.0 & 52.1 & $10.30 \%$ & $12.35 \%$ \\
\hline Supplementary Security Income (SSI) & 26.2 & 39.0 & $0.15 \%$ & $-1.78 \%$ \\
\hline Medicare costs & 550.8 & 710.5 & $0.01 \%$ & $-2.92 \%$ \\
\hline Medicaid costs & 156.2 & 227.1 & $1.19 \%$ & $-2.95 \%$ \\
\hline $\begin{array}{l}\text { Total medical costs for aged 51+ (Billion } \\
\text { dollars) }\end{array}$ & $1,418.9$ & $1,780.9$ & $0.03 \%$ & $-2.55 \%$ \\
\hline
\end{tabular}

Notes: All dollars in 2004 values 
Table 6 The Effect of Obesity and Smoking on Life Expectancy and Medical Spending

\begin{tabular}{|c|c|c|c|c|}
\hline \multicolumn{5}{|c|}{ Smoking } \\
\hline & $\begin{array}{r}\text { Non- } \\
\text { smokers }\end{array}$ & $\begin{array}{l}\text { Former } \\
\text { smokers }\end{array}$ & $\begin{array}{l}\text { Current } \\
\text { smokers }\end{array}$ & $\begin{array}{r}\text { Current smokers } \\
\text { turned into non- } \\
\text { smokers }\end{array}$ \\
\hline$\%$ of cohort & $38.80 \%$ & $36.10 \%$ & $25.10 \%$ & \\
\hline Life expectancy & 35.0 & 31.9 & 25.8 & 33.6 \\
\hline Lifetime Medicare spending & 84,002 & 76,231 & 63,439 & 85,042 \\
\hline \multicolumn{5}{|c|}{ Difference relative to normal weight } \\
\hline Additional life expectancy & & -3.1 & -9.2 & -7.7 \\
\hline \multicolumn{5}{|l|}{$\%$ additional lifetime Medicare } \\
\hline spending & & $-9.3 \%$ & $-24.5 \%$ & $-25.4 \%$ \\
\hline \multicolumn{5}{|c|}{ Obesity } \\
\hline & $\begin{array}{r}\text { Normal- } \\
\text { weight }\end{array}$ & Over-weight & Obese & $\begin{array}{r}\text { Obese turned into } \\
\text { normal weight }\end{array}$ \\
\hline$\%$ of cohort & $28.50 \%$ & $43.20 \%$ & $28.30 \%$ & \\
\hline Life expectancy & 33.0 & 31.4 & 30.6 & 32.4 \\
\hline Lifetime Medicare spending & 72,399 & 75,579 & 80,737 & 74,473 \\
\hline \multicolumn{5}{|l|}{ Difference relative to non-smoker } \\
\hline $\begin{array}{l}\text { Additional life expectancy } \\
\% \text { additional lifetime Medicare }\end{array}$ & & -1.6 & -2.3 & -0.6 \\
\hline spending & & $4.4 \%$ & $11.5 \%$ & $2.9 \%$ \\
\hline
\end{tabular}

